17

\title{
Cohesive zone model properties for evaluating delamination of spray-applied fire-resistive
} materials from steel structures

\author{
Amir Arablouei ${ }^{1}$ and Venkatesh Kodur ${ }^{2}$, P. Eng., F.ASCE
}

1. Ph.D. Candidate, Department of Civil and Environmental Engineering, Michigan State University, East Lansing, Michigan.

2. Professor, Department of Civil and Environmental Engineering, Michigan State University, East Lansing, Michigan.

Tel: 517353 9813; E-mail: kodur@egr.msu.edu

\section{Abstract}

This paper presents cohesive zone model (CZM) fracture properties of spray-applied fire-resistive material (SFRM) for modeling delamination of fire insulation from steel structures. For characterizing cohesive zone properties, namely cohesive strength, cohesive fracture energy and cohesive displacement ductility, a set of experiments are conducted on three types of commercially available SFRM namely medium density Portland cement-based, medium density gypsum-based and mineral fiber-based. Data from experiments is utilized to develop a cohesive stress-displacement relationships in both mode-I and mode-II delamination. The recorded stress-displacement relationship indicates noticeable strain-softening zone verifying that SFRM is not a completely brittle material, rather, it is quasi-brittle.

Keywords: Cohesive zone model, Cohesive strength, Fracture energy, Displacement ductility, Delamination 
20 Steel is one of the primary materials used in structural framing of buildings due to numerous advantages

21 steel offers such as high strength-to-weight ratio, high level of ductility and ease in fabrication and

22 construction process. However, steel structures, in general, do not exhibit favorable fire-resistance due to

23 high thermal conductivity of steel, slender sectional shapes and rapid deterioration of strength and

24 modulus properties of steel with temperature. Hence, steel structures are to be provided with fire

25 insulation to achieve required fire resistance ratings as specified in building codes. This is often achieved

26 through spray applied fire resistive materials (SFRM) that are externally applied to surface of steel

27 structural members. During extreme loading events such as earthquake, blast and impact, there is a high

28 possibility that active fire protection systems get compromised by ruptured water supply piping system

29 and delayed response for firefighting (Mousavi et al. 2008). In such scenarios, adequate fire resistance of

30 structure is the only line of defense for overcoming the damage or collapse of structural systems.

31 Therefore, fire performance of steel structures relies entirely on the effectiveness of fire insulation applied

32 on structural members.

33 SFRM is widely used as fire insulation material due to number of advantages it offers over other 34 insulation materials, including low thermal conductivity, light weight, cost-effectiveness and ease of 35 application (Kodur and Shakya, 2013). The main function of SFRM is to delay the temperature rise in 36 steel, and thus slow down the degradation of stiffness and strength properties of steel when exposed to 37 fires.

38 Effectiveness of SFRM during fire, following impact or earthquake, entails ensuring stable fracture 39 resistance at steel-SFRM interface such that SFRM would not delaminate during these extreme loading 40 events. However, recent experiences have shown opposite. For instance, the progressive collapse of WTC 41 twin towers was partially attributed to loss of fire insulation resulting from high impact loads (FEMA 42 2002, NIST 2005). These incidents have led to a major debate with respect to the role of fire insulation on 
structural integrity and resiliency of high-rise buildings under extreme loading events (NIST, 2005).

44 Limited experiments have also clearly demonstrated that SFRM does not possess enough fracture 45 toughness to remain intact during cyclic loading (Braxtan, Pessiki 2011b). Such delamination or damage 46 to SFRM can strongly jeopardize the fire performance of steel structures (Gu and Kodur, 2011).

47 For evaluating post-impact or post-earthquake fire performance of steel structures, it is of crucial 48 importance to have comprehensive knowledge regarding the extent of SFRM damage during impact or 49 earthquake loading. However, in current fire safety provisions, owing to lack of adequate knowledge on 50 delamination of SFRM from steel structures, as well as lack of cohesive fracture properties of SFRM, the 51 effect of extreme loading events, such as fire following earthquake or impact, on fire performance of steel 52 structures, is not addressed. This serious shortcoming in current provisions necessitates developing a 53 robust approach to predict the delamination of SFRM from steel structures. Developing such knowledge 54 is one of the imperative steps towards rational design and assessment of post-impact and post-earthquake 55 fire performance of steel structures.

56 Fracture mechanics and Cohesive Zone Model (CZM) approach has proven to be a powerful tool for 57 simulating delamination in composites and adhesive joints (Camanho et al., 2003; Alfano et al., 2009). 58 Also, Alfano et al. (2011) used a potential-based CZM to simulate debonding in Al/epoxy T-peel joints. A 59 fundamental step associated with the application of CZM technique is determination of CZM constitutive 60 parameters, namely cohesive strength, cohesive fracture energy and shape of traction-separation law. A 61 new method was assessed by Alfano et al. (2015) to identify CZM in which finite element simulations 62 and full field kinematic data are combined. However, there is limited data in literature on the cohesive 63 zone properties of SFRM for modeling the delamination of SFRM from steel structures.

64 This paper presents cohesive zone model (CZM) fracture properties of spray-applied fire-resistive 65 material (SFRM) for modeling delamination of fire insulation from steel structures. To develop the 66 cohesive zone properties for three types of commercially available SFRM, a series of material property 
67 tests is carried out. The cohesive parameters are evaluated for both normal and shear modes, namely

68 mode-I and mode-II fracture. Subsequently, a fracture mechanics-based numerical approach incorporating

69 CZM (Kodur and Arablouei, 2013) is used to simulate the conducted tests in which the cohesive laws,

70 developed using experimental data, are implemented.

\section{Fracture mechanics of SFRM}

72 Spray-applied fire-resistive material (SFRM) is commercially available in cementitious and mineral-fiber-

73 based forms. Cementitious-based SFRM is further grouped under two categories; gypsum-based SFRM

74 that comprises gypsum and vermiculite, and Portland-cement based SFRM that is composed of Portland

75 cement and vermiculite. Mineral-fiber-based fire insulation comprises of Portland cement and mineral

76 wool fiber mixture. Cementitious and mineral-fiber-based SFRM are delivered to the construction site as

77 wet-mix and dry-mix, respectively. Performance of SFRM during extreme loading conditions is highly

78 dependent upon its integrity, constitutive ingredients, and the manner in which insulation is prepared and

79 applied to the steel surface. During application of SFRM on steel structural members, microscopic cracks

80 can develop within bulk SFRM itself, and also at the interface between steel and SFRM, mainly due to

81 high shrinkage and low tensile strength of SFRM. With increase in loading, that can occur under extreme

82 loading conditions steel structures undergo high level of deformations. Consequently, existing

83 microcracks within SFRM can widen and propagate to the steel-SFRM interface leading to partial or full

84 delamination of fire insulation.

85 Cementitious materials can be considered as two-phase composites comprising of a homogeneous phase

86 and a particle phase (Modeer, 1979). Hence, in cementitious SFRM, the matrix is composed of hydrated

87 cement gels or gypsum paste and the vermiculite particles form the reinforcement. This way the fracture

88 properties of SFRM can be taken to be the average of individual properties of the two phases and the

89 interfacial bond between the phases (Cotterell and Mai, 1996). Given the fact that cement or gypsum

90 constitutes nearly 70 percent of SFRM, both of which are cementitious materials, the fracture mechanics 
91 of SFRM is expected to be analogous to the one developed for a cementitious material. Considering the

92 extensive amount of research (Cotterell and Mai, 1996) on the application of fracture mechanics for

93 cementitious material such as cement paste and concrete, postulated fundamental principles can provide

94 worthwhile direction for comprehending the delamination phenomenon in SFRM based on fracture

95 mechanics principles.

96 Fig. 1 illustrates a typical vicinity of crack in cementitious material and associated fracture process zone

97 (FPZ) developed at the crack tip. Within the FPZ, microcracking and debonding between the cement and

98 the aggregates occurs causing strain-softening behavior in this zone. In fact, the size of the FPZ plays a

99 crucial role in the application of fracture mechanics principles for cementitious materials. The size of

100 fully developed FPZ in cementitious materials is usually large. For instance, cement paste has FPZ size in

101 the order of a millimeter (Higgins and Bailey, 1976), and the FPZ in mortar is around $30 \mathrm{~mm}$ (Hu and

102 Wittmann, 1989). Although cementitious materials behave elastic outside the FPZ, application of classical

103 linear elastic fracture mechanics (LEFM) theory, which is based on single parameter namely stress

104 intensity factor, is highly suspicious owing to large size of localized FPZ at crack tips. In addition,

105 application of LEFM theory entails assuming the location of initial crack, as well as crack propagation

106 path, which makes computational process cumbersome and unmanageable, especially in 3D problems.

107 As a more rigorous alternative, Cohesive Zone Model (CZM) approach can be adopted to tackle the effect 108 of FPZ size on fracture process in materials (Dugdale, 1960 and Barenblatt, 1962). In fact, it was first 109 proposed by Dugdale (1960) to lump the plastic zone at crack tip into a narrow band along which the 110 crack faces are subjected to constant stress (steel yield stress). This idealization was later generalized to 111 many other fracture processes where debonding can be localized in a strip-shaped process zone which is 112 called cohesive zone. This cohesive zone, shown in Fig 2b, is characterized by cohesive stresses binding 113 crack faces which are dependent on separation distance between crack faces. Cohesive law, which is 114 material-specific, expresses the relation between traction and separation over the cohesive zone. CZM 115 approach has successfully been applied for characterizing fracture in ductile metals, fiber reinforced 
composite materials, ceramics, concretes, and also for evaluating interfacial delamination between

117 materials (Camanho etl., 2003; Scheider and Brocks, 2006; Turon et al., 2006; Park et al., 2008; Alfano et

118 al., 2009). Application of this technique for modeling delamination between SFRM and steel will

119 comprehensively be explained in subsequent sections.

120 A review of literature indicates that there have been limited studies, both at material and structural levels,

121 on delamination and fracture of fire insulation from steel structures. At material level, Chen et al. (2010)

122 carried out tests to evaluate mechanical and interfacial properties of SFRM, including compressive

123 strength, tensile strength, normal bonding strength and shear bonding strength. However, they did not

124 measure load-displacement response of SFRM-steel interface and reported only maximum strength

125 attained at fracture. Braxtan and Pessiki (2011a) evaluated bond strength of both wet-mix and dry-mix

126 SFRM through tests on small scale steel coupons. They also studied the effect of surface mill finish of

127 steel on bond performance. Based on these tests they reported that the bond strength is three times higher

128 for wet mix than that for dry mix, and mill finish can considerably degrade adhesion strength between dry

129 mix SFRM and steel. However, they did not provide any load-displacement response at SFRM-steel

130 interface. These tests, obviously, do not provide needed material data for studying fracture mechanics of

131 SFRM thoroughly. Tan et al. (2011) proposed a test method for measuring adhesion of SFRM on steel,

132 which is based on LEFM approach and assumes pre-existing cracks at the SFRM-steel interface. Tan et

133 al. (2011) conducted a set of experiments on thin steel plates insulated with thick SFRM. While holding

134 the SFRM in-place, the end of steel coupon was peeled off with a constant displacement rate and the

135 corresponding applied load was measured. However, this test only measures the fracture energy in mode-I

136 fracture, while carrying the drawback of neglecting the effect of FPZ size. Therefore, a new test method

137 that can measure critical facture energy $\left(G_{c}\right)$ in mode-II fracture, is needed for evaluating critical

138 properties of SFRM for simulating delamination.

139 At structural level, Braxtan and Pessiki (2011b) studied damage pattern in SFRM on a beam-column

140 assembly subjected to quasi-static cyclic loading through large-scale experiments, where the cyclic 
141 loading represented a strong seismic event. Substantial damage of SFRM in bottom flange of beam and

142 partial damage of SFRM in web of beam were observed. Wang et al. (2013) conducted large scale 143 experiments to investigate failure pattern of SFRM applied on cantilever steel columns subjected to large

144 static and cyclic moments at the bottom of the column. The authors concluded that adhesion of SFRM to 145 steel remains weak and noticeable peel-off of SFRM from steel surface occurs on the onset of large 146 moments on the column.

147 Review of literature indicates that there is serious lack of understanding regarding the fracture 148 performance of SFRM both at material and structural levels. Therefore, a new test method is developed 149 for measuring stress-displacement relationship of SFRM over FPZ in both modes of fracture, namely 150 mode-I and mode-II, by taking into account size of the FPZ.

\section{Cohesive zone model concepts}

152 In recent years, the concept of CZM is well-accepted to be an effective method for studying fracture 153 mechanics problems through finite element models (Xu and Needleman, 1994; Alfano and Crisfiled, 154 2001). In essence, CZM establishes a linkage among micromechanical fracture mechanisms and 155 macroscopic structural deformation field by rendering fracture parameters into a material constitutive 156 model. Fig. 2 depicts the application of CZM concept to SFRM-steel interface where traction-separation 157 relationship is shown over the cohesive surface. Fracture process at interface starts with crack initiation, 158 once the cohesive stress reaches cohesive strength $\left(\sigma_{\max }\right)$ of SFRM. Crack initiation is followed by strain159 softening along the localized cohesive zone. As such, interfacial opening displacement increases from 160 zero to failure displacement $\left(\delta_{\mathrm{f}}\right)$. This leads to complete delamination and appearance of new traction free 161 crack faces.

162 There are numerous CZMs proposed in literature to cope with different material types and practical 163 situations. The models developed by Hillerborg et al. (1976), Mi et al. (1998) and Alfano and Crisfield 164 (2001) are a bilinear type. Xu and Needleman (1994) proposed an exponential form of traction-separation 
relation. Trapezoidal cohesive law was proposed by Tvergaard and Hutchinson (1996) to deal with fracture in adhesive joints. Among other models, bilinear cohesive zone model has successfully been utilized by many researchers for modeling delamination of interfaces (Alfano and Crisfiled, 2001; Camanho et al., 2003; Alfano et al., 2009; Atas et al., 2012; Ye and Chen, 2011; Lee et al., 2010). Bilinear model obviously assumes a linear softening rule; however, the other alternatives for softening part of the cohesive zone model are bilinear, exponential and higher polynomials. These types of 171 softening laws, established for concrete, have been evaluated by Hofstetter and Meschke (2011). Alfano 172 (2006) evaluated the influence of the shape of the interface law on the application of cohesive zone 173 models and concluded that the degree of influence that shape of the cohesive law can impose depends on 174 the ratio between the interface toughness and the stiffness of the bulk material. For a typical double175 cantilever beam test, the solution was found to be practically independent from the shape of the cohesive 176 law. While the difference among predictions of linear and exponential softening laws was negligible, the 177 linear softening law always demonstrated the superior efficiency in terms of CPU time. Given the fact 178 that it is intended to apply the developed cohesive laws in predicting the delamination of fire insulation 179 from steel structures in practical scales, CPU time will be extremely crucial. Hence, a bilinear traction180 separation law proposed by Alfano and Crisfield (2001), which can capture the accumulative 181 delamination during unloading and subsequent reloading, is adopted in this study.

182 Fig. 3 shows CZM constitutive relations for SFRM in both normal (mode-I) and tangential (mode-II) 183 directions. The model has a linear elastic portion followed by a linear softening part. Delamination is 184 initiated when the contact stress at the SFRM-steel interface reaches cohesive strength $\left(\sigma_{\max }\right.$ or $\left.\tau_{\max }\right)$ and subsequently progresses until the contact stress reaches zero value, the point at which delamination is completed. Once completely delaminated, further separation occurs without any contact stress. The 187 delaminated surfaces may interact again, however, the contact behavior will be a standard one (i.e. 188 frictional contact). If unloading takes place at any point on softening part, traction-separation follows a 189 linear response and decreses to zero stress. Subsequent reloading does not follow the original stiffness, 

instead takes the previous unloading path with reduced stiffness. This way, the effect of partial 191 delamination and damage accumulation is taken into consideration. The analytical expression for mixed 192 mode delamination (combination of constitutive relations depicted in Fig. 3) can be represented as:

$193\left\{\begin{array}{l}\sigma \\ \tau\end{array}\right\}=\left\{\begin{array}{l}K_{n} \delta_{n}(1-d) \\ K_{t} \delta_{t}(1-d)\end{array}\right\}$

194 where, $\sigma$ and $\tau$ are normal and shear cohesive stresses, $K_{n}$ and $K_{t}$ are normal and tangential contact 195 stiffness, $\delta_{n}, \delta_{t}$ are normal separation and tangential slip distance, and $d$ is damage parameter which is 196 expressed as:

$197 \quad d=\left(\frac{\Delta-1}{\Delta}\right) \chi \quad 0 \leq d \leq 1$

198 where, $\Delta=\sqrt{\left(\frac{\delta_{n}}{\delta_{n, o}}\right)^{2}+\left(\frac{\delta_{t}}{\delta_{t, o}}\right)^{2}}$

199 in which $\delta_{n, o}$ and $\delta_{t, o}$ are separation distances corresponding to normal and shear cohesive strength, 200 respectively and the parameter $\chi$ is given as:

$201 \chi \chi=\frac{\delta_{n, c}}{\delta_{n, c}-\delta_{n, o}}=\frac{\delta_{t, c}}{\delta_{t, c}-\delta_{t, o}}$

202 in which $\delta_{n, c}$ and $\delta_{t, c}$ are normal and tangential separation at the end of cracking, respectively.

203 For $\Delta \leq 1$ the damage parameter is zero $(d=0)$ and for $\Delta>1, d$-value falls between zero and $1(0<d \leq$ 204 1). Note that, in $3 \mathrm{D}$ models isotropic behavior is assumed in terms of tangential slip distance:

$205 \delta_{t}=\sqrt{\delta_{t, 1}^{2}+\delta_{t, 2}^{2}}$

206 where, $\delta_{t, 1}$ and $\delta_{t, 2}$ are tangential slip distance components. Fracture energies $\left(G_{n}\right.$ and $\left.G_{t}\right)$ at any 207 displacement level are calculated as: 
$208 G_{n}=\int \sigma d \delta_{n}$

$209 G_{t}=\int \tau d \delta_{t}$

210 The normal and tangential critical fracture energies $\left(G_{n c}\right.$ and $\left.G_{t c}\right)$ are computed as:

$211 G_{n c}=\frac{1}{2} \sigma_{\max } \delta_{n, c}$

$212 G_{t c}=\frac{1}{2} \tau_{\max } \delta_{t, c}$

213 For decoupled fracture modes, delamination occurs once the current energy level reaches a critical value,

214 whereas for mixed mode delamination an interaction curve needs to be defined since both normal and

215 tangential energies contribute to total fracture energy. In this study, a power law criterion established to

216 predict delamination propagation under mixed mode loading is used which is prevalent in fracture

217 mechanics (Alfano and Crisfield 2001):

$218\left(\frac{G_{n}}{G_{n c}}\right)+\left(\frac{G_{t}}{G_{t c}}\right)=1$

219 where $G_{n}$ and $G_{n c}$ are normal current and critical fracture energy; and $G_{t}$ and $G_{t c}$ are tangential current and

220 critical fracture energy.

\section{Determination of cohesive zone properties of SFRM}

222 As outlined in previous sections, to predict the crack propagation at SFRM and steel interface it is

223 indispensable to establish the constitutive relations of SFRM in FPZ, namely cohesive laws. In this

224 section, test procedures adopted to determine cohesive zone properties are presented.

\section{4.1 Test procedures to evaluate cohesive zone properties}

226 There are, in general, two approaches for obtaining stress-displacement relationship in FPZ of

227 cementitious materials; direct approach and indirect approach. In direct approach, stress-displacement is

228 measured by means of a tension test for Mode I fracture (Peterson, 1985; Reinhardt, 1987; Gu and Zhang, 

of loading, localization of deformation occurs in the FPZ once the maximum load has been attained

231 (Cotterell and Mai, 1996). Specimen dimensions must be large enough to accommodate full development 232 of the FPZ across the tensile area. Stress-displacement relationship obtained from a tension test can 233 directly deliver all three CZM parameters namely, cohesive stiffness, cohesive strength and fracture 234 energy. No further numerical work is therefore required for extracting CZM parameters. However, the 235 fracture evolution across the tensile area must be uniform; otherwise local instabilities such as "bumps" 236 are observed in stress-displacement curve (Hordijk et al., 1987).

237 There are various indirect methods proposed in the literature for deriving stress-displacement relationship 238 in FPZ of cementitious materials. For instance, Li's approach (1987) involves measurement of $J$-integral 239 and crack tip opening displacement (CTOD) to obtain the stress-displacement curve. In this method, two 240 specimens have to be used which makes interpretation of results difficult due to inhomogeneous behavior 241 of cementitious materials. Indirect approach has also extensively been used for composite materials and 242 interface of two materials (Sorensen and Jacobsen, 2003; Gordnian et al., 2008; Lee et al. 2010; Valoroso 243 et al. 2013). In recent years, Double Cantilever Beam (DCB) specimens (ASTM D5528, 2013) and End 244 Notched Flexure (ENF) (ASTM WK22949, 2009) specimens are widely utilized to extract the fracture 245 energy in pure modes I and II, respectively. However, fracture energy is the only outcome from these 246 tests. Two other parameters of cohesive laws, namely cohesive stiffness and cohesive strength, are 247 therefore to be determined through numerical modeling. To extract theses parameters, an ideal stress248 displacement curve is assumed and numerical simulation is carried out. The predicted overall load249 displacement relationship is compared to the experimental behavior and this iterative process is repeated 250 until the best agreement is obtained between experimental and simulation results. However, due to mesh 251 sensitivity of cohesive solutions, the above explained computational effort can be quite significant and the 252 predicted cohesive zone properties may not be accurate. In fact, sensitivity analyses have shown that 253 utilizing global load-displacement relationship for obtaining cohesive properties through an iterative 
process, does not always lead to extracting both cohesive stress and cohesive energy (Alfano et al., 2011).

To overcome above explained difficulties associated with identification of traction-separation laws using

257 cohesive zone behavior more rigorously. This new method is based on recent developments in the area of

258 non-contact optical techniques and utilizes Integrated Digital Image Correlation (I-DIC) concepts.

259 With respect to fire insulation, DCB and ENF tests cannot be used because SFRM does not contribute to the structural capacity (strength) of SFRM-steel assembly. That is, delamination at SFRM-steel interface will not cause any softening in the overall load-displacement relationship. Single Cantilever Beam (SLB) specimens proposed by Tan et al. (2011) to measure fracture energy of SFRM in pure Mode I entails using a very thin steel substrate $(0.35 \mathrm{~mm})$ which may affect the interfacial fracture phenomenon. Tan et al.'s (2011) test is based on LEFM theory and therefore does not account for the strain-softening in FPZ. Further, no testing procedure has so far been proposed for measurement of fracture energy in pure ModeII at SFRM-steel interface. Therefore, direct approach is adopted in this study to establish cohesive laws

267 for mode-I and mode-II delamination at steel-SFRM interface.

\subsection{Materials and specimen geometry}

269 For evaluating fracture-based cohesive properties, three types of commercially available SFRM that are 270 commonly used in building applications, have been selected. The generic type of these three SFRMs is 271 summarized in Tab. 1. Fig. 4 illustrates the overall plate geometry and the specimens after saw cutting. 272 All specimens were prepared at the manufacture's SFRM laboratory. After 6-weeks of curing, the 273 specimens were carefully shipped to Michigan State University's Civil and Infrastructure Laboratory for 274 fracture tests. Two sets of specimens, shown in Fig. 4, were tested for each SFRM type. The specimens 275 were carefully cut to the desired dimensions. The clear space left between specimens is large enough to fit 276 the clamps in between for constraining the specimen plate into the testing machine. Tensile test specimens 277 measured $76.2 \times 76.2 \times 25.4 \mathrm{~mm}$ and shear test specimens measured $101.6 \times 25.4 \times 25.4 \mathrm{~mm}$. With 
respect to size of specimens, it was attempted to adopt as large specimens as possible to reduce the size

279 effects and hence generate as realistic data as possible which can be applicable in practice. The issue of

280 size effect has been studied by Bazant (1984), Bazant and Kazemi (1990) and Bazant and Kazemi (1991)

281 for concrete and rock.

\subsection{Experimental setup for mode-I delamination}

283 A special test setup was designed for undertaking delamination tests on SFRM insulated steel plates to 284 measure normal cohesive stress-displacement response. Details of the test specimens and the testing 285 procedure designed for measuring mode-I delamination properties at steel-SFRM interface is depicted in Fig. 5a and Fig. 6a. A plywood block with thickness of $15 \mathrm{~mm}$ is carefully drilled at the center to which an eyebolt is screwed in. The wooden block is glued on top of tensile specimen using wood glue. After gluing wooden block to SFRM, wood surface is leveled and clamped to the steel plate to make a perfectly flat surface. After 24-hours, the specimens are unclamped and prepared for testing. The test is carried out on an electromechanical material testing system (MTS) shown in Fig. 6a. The steel plate is clamped to an I-beam, which is connected to bottom actuator, to prevent deformation of plate during the test. The eyebolt is connected to the upper rigid block using a shackle-eye nuts-threaded rod assembly. Special care is taken to ensure that no eccentricity exist between MTS loading direction and specimen center. Displacement-controlled load is applied on the specimens and load-displacement relationship is recorded while the loading rate is kept constant at $1 \mu \mathrm{m} / \mathrm{sec}$. Test is terminated once the full fracture of SFRM occurs and specimen can no longer withstand any further load. For each SFRM type, 12 tests were 297 conducted in mode-I delmaination.

\subsection{Experimental setup for mode-II delamination}

299 Direct shear test is conducted to measure the stress-displacement response in mode-II delamination at the interface of SFRM and steel plate. The specimen details and testing method is illustrated in Fig. 5b and Fig. 6b. The SFRM block is pushed against the steel plate thereby inducing direct shear stresses at the 
interface of steel and SFRM. The width of the test specimen along loading direction was chosen to be small enough to preclude cohesive failure within the SFRM. A small gap was introduced between the loading plate and test specimen plate so that friction between two plates is eliminated. The test is carried out through a displacement control loading technique with a constant displacement rate of $1 \mu \mathrm{m} / \mathrm{sec}$. The stress-displacement recording is continued until the SFRM block is fully delaminated from steel surface

307 and the total applied load returns to zero value. For each SFRM type, 12 tests were carried out in mode-II 308 delmaination.

\subsection{Elastic modulus tests}

The elastic modulus for three types of SFRM was determined by conducting compression tests on SFRM blocks of $50.8 \mathrm{~mm} \times 50.8 \mathrm{~mm} \times 50.8 \mathrm{~mm}$ size. Displacement controlled loading was applied with a

312 constant displacement rate of $1 \mu \mathrm{m} / \mathrm{sec}$. The measured elastic modulus on three types of SFRM is listed in 313 Tab. 2.

\section{Results from cohesive zone property tests}

315 The force-displacement relationships recorded from tensile tests are shown in Fig. 7 for three types of 316 SFRM insulated specimens. It is apparent that the response of Portland cement-based SFRM is relatively 317 brittle as compared to the gypsum-based and mineral fiber-based SFRM. For gypsum-based and mineral 318 fiber-based SFRM types, interfacial force rises almost linearly to critical cohesive strength, and 319 subsequently, decreases with increasing normal displacement. The softening behavior observed in the 320 force-displacement curves, confirms that the size of fully developed FPZ is noticeable for gypsum-based 321 and mineral fiber-based SFRM. Even in the case of Portland cement-based SFRM, there is no rapid load 322 drop as would be the case for elastic-brittle materials. For this SFRM type, force-displacement curve is 323 nonlinear up to the peak load which is followed by a sharp drop to 20 percent of peak load as can be seen 324 from force-displacement response in Fig. 7. Then the load response slowly diminishes to zero with further 
325 interfacial deformation. Ultimate fracture displacement in this case is higher than those obtained for 326 gypsum-based and mineral fiber-based SFRM.

327 In all specimens, prior to reaching to cohesive strength (peak load) there was no sign of crack 328 development throughout the specimen. However, once damage is localized and FPZ formation starts, 329 cracks started appearing in decay phase of force-displacement curve and get fully developed and visible 330 upon reaching to the failure displacement. Delayed development of FPZ can be attributed to the fact that 331 in plain tensile specimens no initial crack or notch is introduced. Consequently, this is no focus point for 332 the formation of FPZ and thus dispersion of initial microcracking occurs. Since SFRM is substantially 333 softer than steel $\left(\mathrm{E}_{\mathrm{SFRM}}=30 \mathrm{MPa}<<\mathrm{E}_{\text {steel }}=200 \mathrm{GPa}\right)$ and also the applied loading on the specimen is very low 334 (maximum $0.4 \mathrm{kN}$ ), deformation of steel accessories used in the tensile test has a negligible influence on 335 the recorded displacement. In addition, the elastic contribution from FPZ can be neglected because FPZ is 336 narrow compared with the thickness of specimen. However, the contribution of bulk SFRM to elastic 337 deformation before reaching to cohesive strength should be accounted for. As will be shown shortly, the 338 compliance of bulk SFRM affects the initial elastic response and thus the associated energy and 339 displacement are removed from stress-displacement curves while establishing cohesive laws.

340 From cohesive strength viewpoint, Portland cement-based SFRM possesses the highest strength, while 341 gypsum-based SFRM possesses moderate strength and mineral fiber-based SFRM exhibits the least 342 cohesive strength as can be seen in Fig. 7. Cohesive stiffness also decreases from Portland cement-based 343 SFRM to gypsum-based SFRM, and from gypsum-based SFRM to mineral fiber-based SFRM, as was the 344 case for cohesive strength. Further, as is apparent from the area under each curve, Portland cement-based 345 SFRM offers the highest level of fracture energy, while gypsum-based SFRM and mineral fiber-based 346 SFRM exhibit moderate and low level of fracture energy, respectively. It should be noted that, there is 347 substantial difference in fracture energy between Portland cement-based and gypsum-based SFRM, 348 whereas this is not the case with gypsum-based and mineral fiber-based SFRM. Further, it can be seen in 349 Fig. 7 that there is a nonlinear behavior in the case of Portland cement-based SFRM before reaching to 
cohesive strength. In this case, a different microcracking mechanism both at steel-SFRM interface and

351 bulk SFRM can be responsible for the observed nonlinearity.

352 In Mode-II fracture, as is depicted in Fig. 8, all three materials show similar force-displacement trend 353 though with different level of cohesive zone parameters. Shear force at steel-SFRM interface surges to the 354 maximum cohesive strength and subsequently reduces smoothly as the microcracking activity is 355 completed in FPZ and failure crack tip displacement is attained. Hence, in shear mode of delamination, 356 ductile behavior is dominant in all three types of SFRM, which once more endorses the fact that the size 357 of FPZ is considerable for SFRM. Portland cement-based SFRM provides the superior performance both 358 in terms of cohesive strength and fracture energy. Gypsum-based SFRM performs better than mineral 359 fiber-based SFRM; however, the level of enhancement from mineral fiber-based SFRM to gypsum-based 360 SFRM is not comparable to the one from gypsum-based SFRM to Portland cement-based SFRM. Further, 361 interfacial stiffness is proportional to the level of cohesive strength as was the case with mode-I fracture. 362 Overall, force and displacement peak values shown in Fig. 7 and Fig. 8 suggests that cohesive resistance 363 in mode-II is higher than mode-I. Note that, crack progression phenomenon in shear tests was similar to 364 the one observed in tensile tests, as discussed above.

Displacement ductility over the cohesive zone is an additional parameter of interest for characterizing 366 cohesive zone behavior. This parameter determines the extent of the stain-softening portion of cohesive 367 stress-displacement curve (as illustrated in Fig. 3). Displacement ductility over the cohesive zone $\left(\mu_{n}\right.$ and $368 \mu_{t}$ ) is defined here as the ratio of fracture displacement to displacement corresponding to cohesive 369 strength, as shown in Fig. 3. It is clear from Fig. 7 and Fig. 8 that mineral fiber-based SFRM possesses 370 the highest displacement ductility over cohesive zone, while gypsum-based SFRM possesses moderate 371 ductility, and Portland cement-based SFRM offers the least ductility. It can be inferred that, the softer the 372 SFRM is, the higher the displacement ductility over the cohesive zone will be. 
373 It was indicated in previous section that results of direct test method are acceptable provided the failure 374 surface progresses uniformly through tensile or shear zones. Fig. 9 illustrates the uniform evolution of 375 damage at steel-SFRM interface in tensile and shear tests. In tensile tests, one of the specimens, out of 12 376 tested specimens from Portland cement-based SFRM, did not show this behavior and the result from this 377 specimen was discarded. In shear tests, all 12 specimens developed a uniform shear failure at the steel378 SFRM interface. Also, it was discussed that force-displacement curves for mode-I fracture show ductile 379 behavior in all cases except in the case of Portland cement-based SFRM under tensile loading. Even in 380 this case, it was concluded that the material does not behave purely brittle. In addition, all three types of 381 SFRM demonstrated ductile performance in Mode-II fracture. Therefore, from fracture mechanics 382 perspective, SFRM may be considered as a "quasi-brittle" material, rather than "brittle" material.

383 Average cohesive strength obtained from tensile and shear tests are plotted in Fig. 10. The cohesive 384 stresses are calculated by dividing the recorded force to cross sectional area under tension and shear $385(\sigma=\mathrm{P} / \mathrm{A})$. As is represented by error bars, the scatter in the data is relatively small which proves the 386 reliability of results. The mean values of cohesive strength are tabulated in Table. 2. The shear cohesive 387 strength is almost twice as high as normal cohesive strength for all three types of SFRM. In both normal 388 and shear modes of fracture, Portland cement-based SFRM exhibits the highest cohesive strength, 389 gypsum-based SFRM exhibits average strength and mineral fiber-based SFRM exhibits the least strength. 390 Manufacturer of these SFRMs has only provided the normal cohesive strength (bonding strength) which 391 is included in Table. 2. The normal bonding test (adhesion test) is performed by manufactures according 392 to ASTM E736 (2006). In this method, a metal of plastic disk containing a hook is attached to the surface 393 of SFRM using a quick-setting adhesive. Then, a spring-type weighing scale is attached to the hook and 394 the scale is pulled. The bond is considered acceptable provided the SFRM can endure the applied 395 minimum load. The normal cohesive strength from tests for gypsum-based and mineral fiber-based 396 SFRM are very close to value given by the manufacturer; however, for Portland cement-based SFRM, 
manufacture reports a very high upper bond value for normal cohesive strength which was not observed

398 in the tests carried out in this study.

399 Fig. 11 shows the critical fracture energy measured in mode-I and mode-II fracture tests. The error bars in 400 this case are also fairly small validating reproducibility of fracture energies extracted from the 401 experiments carried out in this study. The order of performance in terms of fracture energy is identical to 402 the one mentioned above for cohesive strength. However, the ratio of shear fracture energy to normal 403 fracture energy is 4 and 5 for gypsum-based and mineral fiber-based SFRM, respectively, while this ratio 404 is close to 2 for Portland cement-based SFRM. Further, irrespective of all differences among the 405 quantities and performances of SFRMs, one fact is very obvious that the amount of critical fracture 406 energy is low. This characteristic of SFRM raises the concern regarding the delamination at SFRM-steel 407 interface when the steel substrate undergoes large strains under the action of extreme loading events on 408 steel structures.

409 To accommodate the experimentally obtained stress-displacement curves with bilinear CZM described in 410 section 3, the concept of equal energy can be adopted as displayed in Fig. 12. The displacement 411 corresponding to cohesive strength can be extracted by equalizing the area under the curve up to 412 experimental culmination displacement with the corresponding area of a triangle in bilinear model. The 413 elastic energy absorbed by bulk SFRM is removed from the total elastic energy. The elastic deformation 414 of bulk SFRM is calculated using Hook's law by knowing the elastic modulus and maximum stress 415 experienced by SFRM during test. The displacement corresponding to cohesive strength is also reduced 416 by elastic deformation of bulk SFRM. Likewise, the failure displacement at cohesive zone can be 417 obtained by associating the total areas under experimental curve (reduced due to compliance of bulk 418 SFRM) and bilinear model. The result of this equalization process is plotted in Fig. 13 and Fig. 14 where 419 CZMs pertaining to mode-I and mode-II fracture for three types of SFRM are shown, respectively. Table 4202 presents the cohesive zone parameters along with elastic modulus for three type of SFRM. These CZMs 
421 can be utilized for simulation of progressive delamination at steel-SFRM interface in different structural

422 assemblies insulated with SFRM.

423 Lastly, the size of the cohesive zone (or in other words, FPZ) is to be predicted prior to identifying the

424 element size in numerical modeling such that enough number of elements span the cohesive zone to 425 ensure as correct dissipation of energy as possible. Turton et al. (2007) have summarized some of the 426 expressions with respect to computation of cohesive zone length. In this study the cohesive zone length is 427 computed using the following expression, given by Hillerborg et al. (1976), for concrete as a cementitious 428 material:

$429 \quad l_{c z}=\frac{E G_{c}}{\left(\sigma_{c o h}\right)^{2}}$

430 in which, $E, G_{c}$ and $\sigma_{c o h}$ are elastic modulus, fracture energy release rate and cohesive strength for fracture 431 mode-I, respectively. The cohesive zone length computed by Eq. (11) for gypsum-based, Portland 432 cement-based and mineral fiber-based SFRM types are $187 \mathrm{~mm}, 481 \mathrm{~mm}$ and $79 \mathrm{~mm}$, respectively. By 433 carefully inspecting Eq. (11), and given the corresponding quantities for SFRM, it is clear that the large 434 size of cohesive zone can be attributed to very low level of cohesive strength (with square power in 435 denominator). The large size of cohesive zone indicates that LEFM is not applicable for evaluating 436 fracture in SFRM. It should be noted that, length of fully developed fracture process zone is size and 437 geometry-dependent. In fact, in small specimens, FPZ cannot fully develop. This issue has been dealt 438 with by Bazant and Kazemi (1990) for concrete and rock. However, there is no research on size of FPZ 439 developed at steel-SFRM interface. The equation (11), which is also termed characteristic length in 440 fracture mechanics literature (Cotterell and Mai, 1996), can only provide an approximate extension of 441 fully developed FPZ at steel-SFRM interface. This equation is utilized in this study to only approximate 442 the size of FPZ (cohesive zone) in order to have an estimation of initial mesh size over the cohesive zone. 443 Nonetheless, mesh sensitivity analyses is performed to ensure that sufficient number of cohesive elements 444 (at least 10 elements) is embedded in cohesive zone to correctly capture the nonlinearity in this zone. 


\section{Numerical simulations}

To demonstrate the usefulness of cohesive zone properties of SFRM in predicting delamination of SFRM from steel structures, two sets of numerical studies is carried out. In the first set of numerical modeling, delamination in two separate modes of fracture are simulated, while in the second set, mixed-mode delamination is modeled. A finite element model developed in ANSYS software (Kodur and Arablouei, 2013 ) is used to simulate delamination phenomenon by implementing the cohesive laws developed in the above discussed experimental program.

\subsection{Numerical modeling of fracture tests}

In the first set of simulations, the fracture tests carried out in this study on three types of SFRM are simulated through finite element model. Steel substrate and SFRM are discretized using 8-noded solid elements available in ANSYS. At the interface, surface-to-surface contact is employed such that steel and SFRM surfaces are discretized using 4-noded target and contact elements, respectively. The proposed cohesive laws developed using experimental data are utilized here as steel-SFRM interface constitutive model. As previously indicated, CZM requires to be coupled to interface elements in order to model progression of delamination. In this study, contact elements are adopted for this purpose. Initially, two surfaces are assumed to be bonded and subsequently, under increasing loading conditions, separation or slip distance is simulated in accordance with corresponding CZM. The test conditions are represented in the numerical model with as much details and accuracy as possible in terms of boundary conditions and geometrical aspects. Boundary conditions and loading methods encountered in experiments, which were illustrated in Fig. 5 and Fig. 6, are adopted in the numerical modeling. Fig. 15 depicts the finite element model generated to predict both modes of fracture observed in the experiments. The model comprises of the steel plate, SFRM, wooden block and eyebolt. The finite element size over the cohesive zone was kept small enough $(2 \mathrm{~mm})$ to eliminate approximation problems. Give the value of characteristic length computed by equation (11), this is a very fine mesh. The minimum number of elements spanning over the 

used by researchers (Falk et al., 2001; Dávila et al., 2001; Moës and Belytschko, 2002). In this study,

471 results of analysis for mesh size of $2 \mathrm{~mm}$ and $5 \mathrm{~mm}$ were identical. SFRM cohesive zone properties

472 derived in the experiments are utilized (Table 2). The cohesive laws depicted in Fig. 13 and 14 are used to

473 trace the interface behavior. The elastic modulus of SFRM, obtained through compression tests was

474 utilized. The steel truss member is assumed to be of A992 $\left(\sigma_{\mathrm{y}}=355 \mathrm{MPa}, \mathrm{E}=200 \mathrm{GPa}\right.$ and $\left.v=0.3\right)$.

\subsection{Numerical modeling of plate-SFRM assembly under tension}

In the second set of simulations, a delamination test reported by Braxtan and Pessiki (2011a) on an insulated steel plate is modeled. Fig. 16a and Fig. 16b depict the test plate setup and geometry, respectively. The test plate measured $1100 \mathrm{~mm}$ long $\times 152 \mathrm{~mm}$ wide $\times 6 \mathrm{~mm}$ thick and was covered with mineral fiber-based SFRM at the central $457 \mathrm{~mm}$ of one face of plates. A distance of $305 \mathrm{~mm}$ was then left bare on each end enabling specimen to fit in universal testing machine's upper and lower jaws. Strain gages were attached to steel plate to measure the strain level during tensile tests. The plate was loaded through displacement control at a loading rate of $1.27 \mathrm{~mm} / \mathrm{min}$.

The finite element model of plate-SFRM assembly is illustrated in Fig. 16c. The steel plate is discretized using 4-noded shell elements (SHELL181) that have three translational and three rotational degrees of freedom at each node. SFRM is discretized using 8-noded solid elements. SFRM-interface behavior is simulated through contact interaction elements by implementing the CZM as material constitutive model. Mesh sensitivity analysis was carried out to find the optimum mesh size. While incrementally reducing the mesh size from $20 \mathrm{~mm}$ to $10 \mathrm{~mm}$, it was found that, there is negligible improvement from mesh size of $12 \mathrm{~mm}$ to $10 \mathrm{~mm}$. The average cohesive properties of mineral fiber-based SFRM derived in this study were used to model bulk SFRM and SFRM-steel interface behavior. The grade of steel used in this plate is $\mathrm{A} 36\left(\sigma_{\mathrm{y}}=325 \mathrm{MPa}, \mathrm{E}=200 \mathrm{GPa}\right.$ and $\left.v=0.3\right)$.

\subsection{Nonlinear solution techniques}


Numerical solution in the case of contact interaction analysis is highly nonlinear making computational

494 efforts cumbersome, even though material properties remain elastic. The contact algorithm used in this

495 study is a "pure penalty" algorithm (ANSYS, 2013) that uses a contact spring to establish a relationship

496 between the two contact surfaces. In contact solutions, convergence problems arise when the response

497 reaches softening zone of CZM. Crisfield et al. (1994) inferred that Newton-Raphson method is not

498 efficient enough due to convergence issues while using either load-controlled (with Arc Length) or

499 displacement-controlled loading. To rectify the problem, Crisfield et al. (1994) proposed line search

500 procedure. In this study, displacement-controlled loading, in conjunction with line search method, is used

501 thereby enhancing the capabilities of Newton-Raphson method to achieve convergence. Nonetheless,

502 convergence issues arise at some load steps which is treated by adopting nonlinear stabilization method

503 provided in ANSYS. Nonlinear stabilization in ANSYS can be understood as adding an artificial damper

504 or dashpot element at each node of an element. The damper element coefficient is then optimized such

505 that the stabilization process will not influence the accuracy of solution.

\section{$506 \quad 7$ Results of numerical simulations}

507 Results from numerical modeling of fracture tests conducted in this study on three SFRM types and plate-

508 SFRM assembly under tension is presented here. In the first set of simulations, the numerical simulations

509 examine the numerical technique at each separate fracture modes. The numerical and experimental results

510 are superimposed in Fig. 17 showing acceptable correlation among two sets of results for three types of

511 SFRM. Both cohesive strength and fracture energy are satisfactorily predicted in this case. For mode-II

512 fracture, the stress-displacement curves are shown in Fig. 18. A quite reasonable agreement can also be

513 seen in Fig. 18 between numerically predicted stress-displacement relationship and the observed

514 experimental behavior. As it can be seen, in both cases, predicted stress-displacement relationship has a

515 bi-linear shape, which is expected due to the fact that the input CZM is bilinear. Above explained two

516 examples of simulation demonstrate that the developed numerical procedure is practically capable of 517 predicting observed fracture mechanisms for both modes of fracture. 
518 In the second set of results, predicted delamination progression on steel plate covered with mineral fiber-

519 based SFRM is shown in Fig. 19 and compared to the one obtained from experiment. The delamination

520 length at the end of steel plate is predicted to be $134 \mathrm{~mm}$ at strain level of $11.8 \varepsilon_{\mathrm{y}}$, while the measured

521 fracture extent is $127 \mathrm{~mm}$ in experiments at strain level of $10.4 \varepsilon_{\mathrm{y}}$. Given the fact that average values of

522 fracture properties were used for SFRM in numerical model, which may not be exactly identical to the

523 SFRM properties in the experiment, the correlation between predicted and measured extent of fracture is

524 fairly satisfactory. This clearly shows the applicability of cohesive zone models proposed in this study for

525 modeling progressive delamination of SFRM from steel structure where mixed-mode delamination

526 governs failure.

\section{Summary and conclusions remarks}

528 In this paper, cohesive zone response properties of fire insulation in mode-I and mode-II fracture was 529 evaluated through a set of direct tensile and shear strength tests on three types of SFRM commonly used 530 in practice. Based on the results outlined in this paper following points are highlighted:

$531 \quad-\quad$ Strain-softening behavior of spray-applied fire-resistive material (SFRM) at steel-SFRM interface

532 clearly infers that SFRM is not a purely brittle material; instead, it is a quasi-brittle material.

$533 \quad-\quad$ Presence of considerable size of fracture process zone in SFRM infers that application of linear 534 elastic fracture mechanics is not suited for characterizing fracture in quasi-brittle type of SFRM 535 and more advanced approaches such as Cohesive Zone Model is to be applied to evaluate realistic 536 response.

537 - Medium density Portland cement-based SFRM possesses the highest cohesive strength and 538 fracture energy while having the least displacement ductility over the cohesive zone.

$539 \quad-\quad$ Medium density gypsum-based SFRM possesses lower cohesive strength and fracture energy, as 540 compared to Portland-cement based SFRM, and has higher displacement ductility over the cohesive zone. 
- Mineral fiber-based SFRM possesses the least cohesive strength and fracture energy but has the highest cohesive ductility.

- Good correlation between predicted and measured fracture response parameters for three types of SFRM and steel plate-SFRM assembly under tension, indicates that the proposed cohesive zone properties, developed through experiments in this study, can be utilized in further sensitivity studies with respect to cohesive zone parameters namely cohesive strength, fracture energy and cohesive ductility. In addition, the proposed cohesive laws can be used for quantifying progressive delamination of SFRM from steel structures subjected to complex loading scenarios.

\section{References}

ASTM D5528 (2013). Standard Test Method for Mode I Interlaminar Fracture Toughness of Unidirectional FiberReinforced Polymer Matrix Composites.

ASTM WK22949 (2009). New Test Method for Determination of the Mode II Interlaminar Fracture Toughness of Unidirectional Fiber-Reinforced Polymer Matrix Composites Using the End-Notched Flexure (ENF) Test.

ASTM E736. Standard test method for cohesion/adhesion of spray fire-resistive materials applied to structural members. Annual Book of ASTM Standards, vol. 04.11. ASTM International: West Conshohocken, 2006.

Atas, A., Mohamed, G.F., Soutis, C., (2012). Modelling delamination onset and growth in pin loaded composite laminates. Composite Science and Technology; 72, 1096-1101.

Alfano, G., and Crisfield, M. A., (2001). Finite element interface models for the delamination analysis of laminated composites: mechanical and computational issues. International Journal for Numerical Methods in Engineering, 50(7), 1701-1736.

Alfano, G. (2006). On the influence of the shape of the interface law on the application of cohesive-zone models. Composite Science and Technology; 66, 723-730.

Alfano M, Furgiuele F, Leonardi A, Maletta C, Paulino GH.( 2009). Mode I fracture of adhesive joints using tailored cohesive zone models. International Journal of Fracture; 157(1-2):193-204.

M. Alfano, G. Lubineau, F. Furgiuele, G. H. Paulino, (2011). On the enhancement of bond toughness for Al/epoxy T-peel joints with laser treated substrates. International Journal of Fracture; 171(2): 139-150. 

models using full-field kinematic data. International Journal of Solids and Structures; 55, pp. 66-78.

570 M. Alfano, F. Furgiuele, G. Lubineau and G. Paulino (2011). Simulation of debonding in Al/epoxy T-peel joints 571 using a potential based cohesive zone model. Procedia Engineering, v. 10, pp. 1760-1765.

572 ANSYS Version 14.5 (2013), [Computer software]. ANSYS, Inc. Canonsburg, PA.

573 Barenblatt, G.I. (1962). Mathematical theory of equilibrium cracks in brittle failure, Advances in Applied 574 Mechanics, 7.

575 Bazant, Z. P. (1984). Size effect in blunt fracture: Concrete, Rock, Metal. Journal of Engineering Mechnaics; 110 576 (4): 518-535.

577 Bazant, Z. P., Kazemi, M. T. (1990). Determination of fracture energy, process zone length and brittleness number 578 from size effect, with application to rock and concrete. International Journal of Fracture; 44: 111-131.

579 Bazant, Z. P., Kazemi, M. T. (1991). Size dependence of concrete facture energy determined by RILEM work-of580 fracture method. International Journal of Fracture; 51: 121-138.

581 Braxtan, N. L., and Pessiki, S. P. (2011a). Bond performance of SFRM on steel plates subjected to tensile 582 yielding.”Journal of Fire Protection Engineering, 21, 37-55.

583 Braxtan, N. L., and Pessiki, S. P. (2011b). Postearthquake fire performance of sprayed fire-resistive material on steel 584 moment frames, ASCE Journal of Structural Engineering, 137 (9).

585 B. Blaysat, J. Hoefnagels, G. Lubineau, M. Alfano and M. Geers (2014). Interfacial debonding quantification by 586 image correlation integrated with double cantilever beam kinematics. International Journal of Solids and Structures. 587 v. 55 , pp. $79-91$.

588 Camanho, P.P, Davila, C.G., and Moura, M.F. DE, (2003). Numerical simulation of mixed-mode progressive 589 delamination in composite material, Journal of Composite Materials, 37 (1415-1438).

590 Chen, S.-W., Chu, J., and Li, G.-Q. (2010). A study on damage mechanism of thick fireproof coating for steel 591 member subjected to monotonic loading. Proceeding of 6th International Conference on Structures in Fire ( $\mathrm{SiF}$ '10), 592 Michigan State Univ., East Lansing, MI.

593 Cotterell B, Mai YW. (1996). Fracture mechanics of cementitious materials. London, UK: Blackie Academic \& 594 Professional, an Imprint of Chapman and Hall. 
Crisfield, M.A., Hellweg, H.B. and Davies, G.A.O. (1994). Failure analysis of composite structures using interface elements, NAFEMS Conference on Application of Finite Elements to Composite Materials, London, UK.

597 Davila CG, Camanho PP, de Moura MFSF, (2001). Mixed-Mode decohesion elements for analyses of progressive 598 delamination. In: Proceedings of the 42nd AIAA/ASME/ASCE/AHS/ASC structures. Structural dynamics and 599 materials conference, Seattle, Washington; April 16-19. 104.

602 Dwaikat, M., Kodur, V., (2011). Modeling fracture and delamination of spray-applied fire-resisting materials under 603 static and impact loads. Journal of Engineering Mechanics, 137 (12).

604 Falk ML, Needleman A, Rice JR, (2001). A critical evaluation of cohesive zone models of dynamic fracture. J Phys 605 IV, Proc: 543-50.

606 FEMA. (2002). World Trade Center building performance study. FEMA Report. No. 403, Washington, DC.

607 Gordnian, K., Hadavinia, H., Mason, P.J., Madenic, E., (2008). Determination of fracture energy and tensile 608 cohesive strength in Mode I delamination of angle-ply laminated composites, 82, 577-586.

609 Guo, Z.H., and Zhang, X.Q., "Investigation of complete stress-deformation curves for concrete in tension", ACI 610 Materials Journal, 84 (4), 1987, 278-285.

611 Gu, L., Kodur, V., (2011). "Role of Insulation Effectiveness on Fire Resistance of Steel Structures under Extreme

612 Loading Events”, J. Perform. Constr. Fac., 25 (4), p277-286.

613 Hilleborg, A., Modeer, M., Peterson, PE., (1976). Analysis of crack formation and growth in concrete by means of 614 fracture mechanics and finite elements, Cement and Concrete Research; 6:773-782.

615 Higgins, D. D., Bailet, J. E., (1976). Fracture measurements on cement paste. Journal of Material Science, 11 (1995616 2003).

617 Hordijk, D.A., Reinhardt, H.W., Cornelissen, H.A.W., (1987). Fracture mechanics parameters of concrete from 618 uniaxial tensile tests as influenced by specimen length. Proceeding of international conference on Fracture 619 Mechanics of Concrete and Rock, Houston (US), 138-149.

620 Hofstetter, G., Meschke, G., (2011). Numerical modeling of concrete cracking. International Center for Mechanical 621 Science. Courses and Lectures - No. 532. Springer Wien NewYork. 
622 Hu, X. Z., Wittmann, F.H., (1989). Fracture process zone and $\mathrm{K}_{\mathrm{r}}$ curve of hardened cement paste and mortar, in 623 Fracture of Concrete and Rock- Recent developments, Shah, S. P., Swartz, S.E. and Barr, B., Eds., Elsevier Applied 624 Science, London, 307.

625 Keller, W.J., Pessiki, S, (2012). Effect of earthquake-induced damage to spray-applied fire-resistive insulation on the response of steel moment-frame beam-column connections during fire exposure, Journal of Fire Protection

627 Engineering, 22(4), 271-299.

628 Kodur, V.K.R., Arablouei, A., (2013). Mechanics based approach for modeling delamination of fire insulation from steel structures. ASCE Journal of Engineering Mechanics, 10.1061/(ASCE)EM.1943-7889.0000753, 04014037.

630 Kodur, V.K.R., Shakya, A.M., (2013). Effect of temperature on thermal properties of spray applied fire resistive 631 materials, Fire Safety Journal, 61, 314-323.

632 Lee, M.J., Cho, T.M., Kim, W.S., Lee, B.C., Lee, J.J., (2010). Determination of cohesive parameters for a mixed633 mode cohesive zone model. International Journal of Adhesion and Adhesives, 30, 322-328.

634 Li, V.C. Chan, C.M. and Leung, C.K.Y. (1987). Experimental determination of the tension-softening curve in 635 cementitious composites, Cement and Concrete Research, 17(3), 441-452.

636 Mi Y, Crisfield MA, Davies GAO, Hellweg HB. (1998). Progressive delamination using interface elements. Journal 637 of Composite Materials; 32(14):1246-72.

638 Mousavi, S., Bagchi, A., and Kodur, A., (2008). Review of post-earthquake fire hazard to building structures, 639 Canadian Journal of Civil Engineering, 35, 689-698.

640 Modeer, M. (1979). A fracture mechanics approach to failure analysis of concrete materials, University of Lund, 641 Report TVBM-1001.

642 Moes N, Belytschko T., (2002). Extended finite element method for cohesive crack growth. Journal of Engineering 643 Fracture Mechanics, 69, 813-833.

644 NIST (National Institute of Standards and Technology), 2005, Final Report on the Collapse of the World Trade 645 Center Towers, NIST NCSTAR1, Gaitherburge, MD, September.

646 Park K, Paulino GH, Roesler JR, (2008). Determination of the kink point in the bilinear softening model for 647 concrete. Engineering Fracture Mechanics. 75(13): 3806-3818. 
652 Scheider., I, Brocks., W., (2006). Cohesive elements for thin walled structures. Computational Material Science $653 \quad 37(1-2): 101-109$.

654 Sorensen, B.F., Jacobsen, T.K., (2003). Determination of cohesive laws by the $J$ integral approach. Journal of 655 Engineering Fracture Mechanics. 70, 1841-1858.

656 Tan, K. T., Christopher, C. W., and Hunston, D. L. (2011). An adhesion test method for spray-applied fire-resistive 657 materials. Fire and Materials, 35(4), 245-259.

658 Tvergaard V, Hutchinson JW., (1996). On the toughness of ductile adhesive joints. J Mechanics and Physics of 659 Solids 44(5):789-800.

660 Turon, A. Camanho, P. P., and Dávila, C. G., (2006). A Damage Model for the Simulation of Delamination in 661 Advanced Composites under Variable-Mode Loading," Mechanics of Materials, Vol. 38(11), 1072-1089.

662 Turon, A., Dávila, C. G., Camanho, P. P., and Costa, J., (2007). An Engineering Solution for Mesh Size Effects in 663 the Simulation of Delamination Using Cohesive Zone Models. Engineering Fracture Mechanics, 74(10), 1665-1682.

664 Valorson, N., Sesa, S., Lepore, M., Cricri, G., (2013). Identification of mode-I cohesive parameters for bonded 665 interfaces based on DCB tests. Journal of Engineering Fracture Mechanics, 104, 56-79.

666 Ye, Q., Chen, P., (2011). Prediction of the cohesive strength for numerically simulating composite delamination via 667 CZM-based FEM. Composites: Part B, 42, 1076-1083.

668 Wang, W-Y., Li, G-O., Kodur, V. (2013). An approach for modeling fire insulation damage in steel columns. 669 ASCE Journal of Structural Engineering, 139(4), 491-503.

670 Xu, X.-P., and Needleman, A. (1994). Numerical simulations of fast crack growth in brittle solids. Journal of the 671 Mechanics and Physics of Solids, 42(9), 1397-1434.

\section{Acknowledgements}

673 This material is based upon work partially supported by the National Science Foundation (NSF) under 674 grant number CMMI-0757900, American Institute of Steel Construction, (through AISC Faculty 
675 Fellowship to Prof. Kodur) and Michigan State University (through Strategic Partnership Grant \# SPG

676 71-4434). Any opinions, findings, and conclusions or recommendations expressed in this paper are those

677 of the authors and do not necessarily reflect the views of the sponsors.

678

679 List of Tables:

680 Tab. 1 Three type of SFRM utilized in experiments

681 Tab. 2 Cohesive zone model parameters obtained in experiment for three types of SFRM

682

683 List of Figures:

684 Fig. 1 Strain-softening at fracture process zone for SFRM

685 Fig. 2 Cohesive zone model concepts at interface of steel structural member and SFRM

686 Fig. 3 Cohesive zone constitutive model for SFRM

687 Fig. 4 Test plate geometry for measuring CZM parameters

688 Fig. 5 Schematic of test assembly for determination of CZM parameters

689 Fig. 6 Test set up designed for measuring CZM parameters at steel-SFRM interface

690 Fig. 7 Normal force-displacement relationship (Mode-I delamination)

691 Fig. 8 Shear force-displacement relationship (Mode-II Delamination)

692 Fig. 9 Fracture at steel-SFRM interface observed in the experiments

693 Fig. 10 Interfacial cohesive strength for three types of SFRM

694 Fig. 11 Interfacial critical fracture energy for three types of SFRM

695 Fig. 12 Determination of bilinear CZM parameters based on experimental results

696 Fig. 13 Bilinear CZM for mode-I fracture determined from experiments

697 Fig. 14 Bilinear CZM for mode-II fracture determined from experiments

698 Fig. 15 Finite element model of SFRM-steel assembly in mode-I and mode-II fracture experiments

699 Fig. 16 Experimental setup and finite element model for plate covered with Mineral fiber-based SFRM

700 Fig. 17 Comparison of force-displacement relationship predicted from numerical model with measured 701 values from experiments for mode-I delamination 
702 Fig. 18 Comparison of force-displacement relationship predicted from numerical model with measured

703 values from experiments for mode-II delamination

704 Fig. 19 Delamination length predicted and measured on a plate covered with Mineral fiber-based SFRM

705

706

Tab. 1 Three type of SFRM utilized in experiments

\begin{tabular}{|c|c|}
\hline Name & Type of SFRM \\
\hline A & Medium density gypsum-based \\
\hline B & Medium density Portland cement-based \\
\hline C & Mineral-fiber-based \\
\hline
\end{tabular}

707

Tab. 2 Cohesive zone model parameters obtained in experiment for three types of SFRM

\begin{tabular}{|c|c|c|c|c|c|c|c|c|c|c|c|c|}
\hline $\begin{array}{l}\text { SFRM } \\
\text { type }\end{array}$ & $\begin{array}{c}\sigma_{\max } \\
(\mathrm{kPa})\end{array}$ & $\begin{array}{c}\boldsymbol{\tau}_{\max } \\
(\mathrm{kPa})\end{array}$ & $\tau_{\max } / \sigma_{\max }$ & $\underset{\left(J / m^{2}\right)}{G_{c n}}$ & $\begin{array}{c}\mathbf{G}_{\mathrm{ct}} \\
\left(\mathrm{J} / \mathrm{m}^{2}\right)\end{array}$ & $\mathbf{G}_{\mathrm{ct}} / \mathbf{G}_{\mathrm{cn}}$ & $\begin{array}{c}\mathrm{K}_{\mathrm{n}} \\
(\mathrm{kPa} / \mathrm{mm})\end{array}$ & $\begin{array}{c}\mathrm{K}_{\mathrm{t}} \\
(\mathrm{kPa} / \mathrm{mm})\end{array}$ & $\mu_{n}$ & $\mu_{t}$ & $\begin{array}{c}E \\
(\mathrm{MPa})\end{array}$ & $\begin{array}{c}\text { Manufacture } \\
\sigma_{\text {max }} \text { range } \\
(\mathrm{kPa})\end{array}$ \\
\hline A & 22.9 & 49.6 & 2.2 & 7.9 & 32.8 & 4.2 & 57.3 & 107.9 & 1.73 & 2.98 & 11.5 & $7.2-20.5$ \\
\hline B & 52.8 & 107.3 & 2.0 & 33.7 & 74.4 & 2.2 & 57.4 & 162.6 & 1.40 & 2.11 & 38.4 & $20.8-409.6$ \\
\hline$C$ & 13 & 24.6 & 1.9 & 4.3 & 22.5 & 5.2 & 39.3 & 61.4 & 2.03 & 4.63 & 2.6 & $7.2-17.9$ \\
\hline
\end{tabular}

708 


\section{FigureV}

\section{Figure 1}

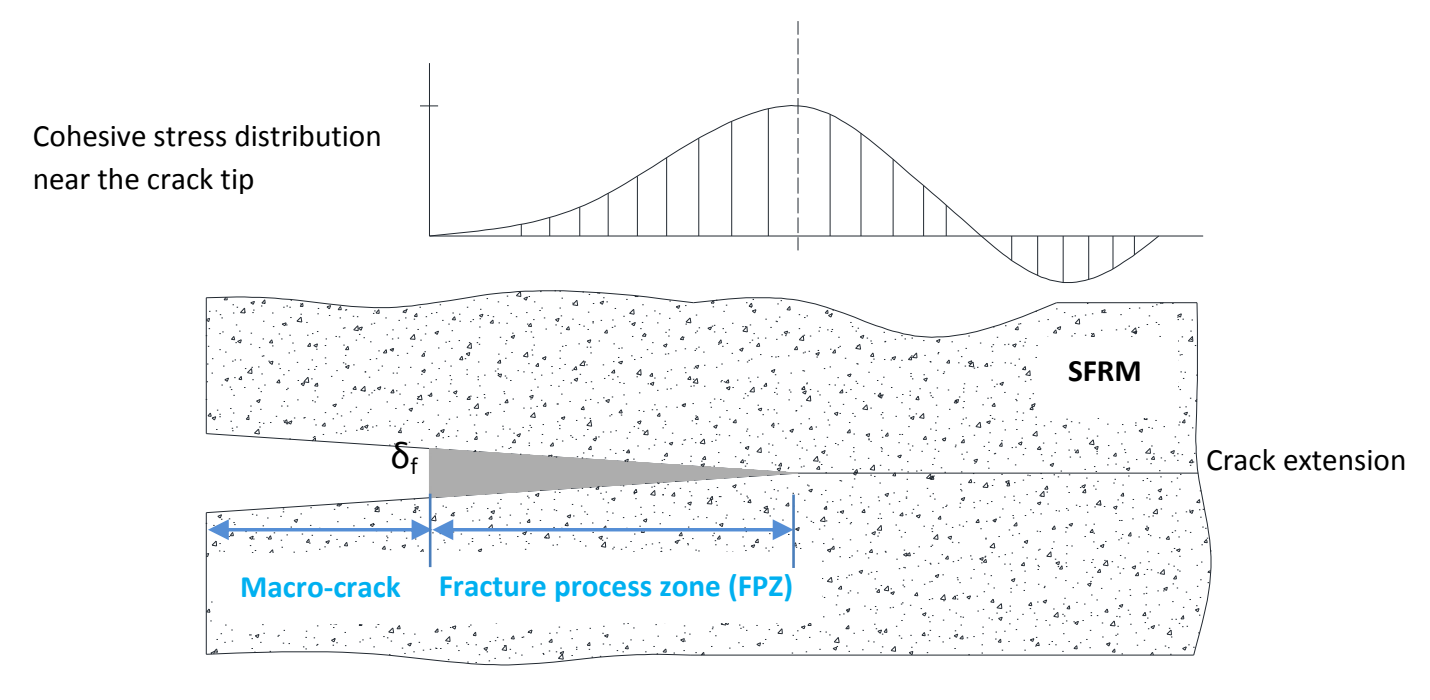

Fig. 1 Strain-softening at fracture process zone for SFRM

Fig. 1 Strain-softening at fracture process zone for SFRM

Cohesive stress distribution near the crack tip

(1)

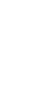


Figure 2
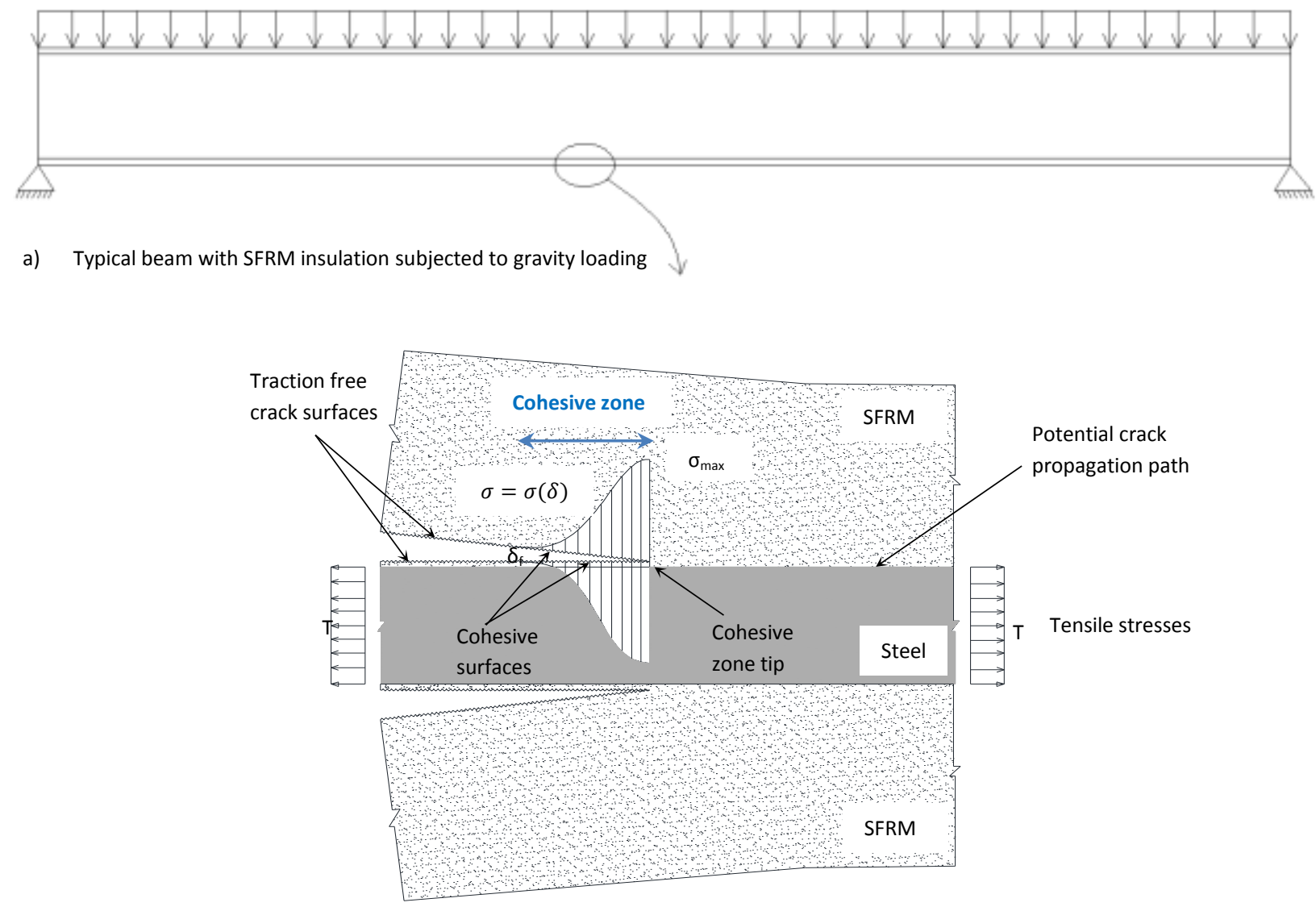

b) Progression of cracks leading to delamination of SFRM at bottom flange of beam

Fig. 2 Cohesive zone model concepts at interface of steel structural member and SFRM 


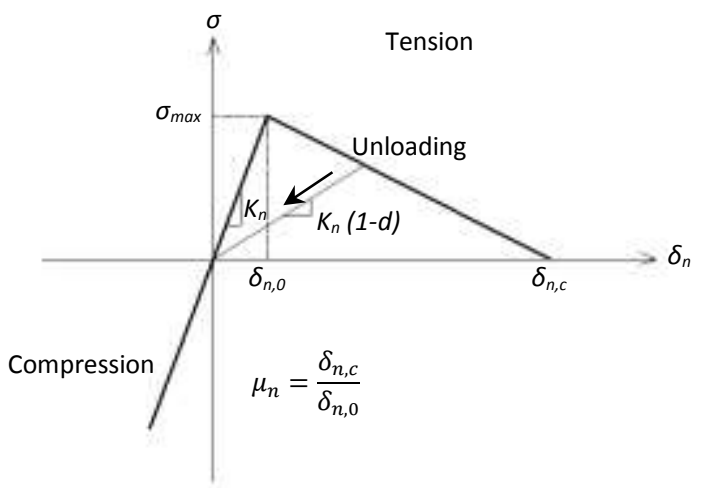

a) Mode-I fracture

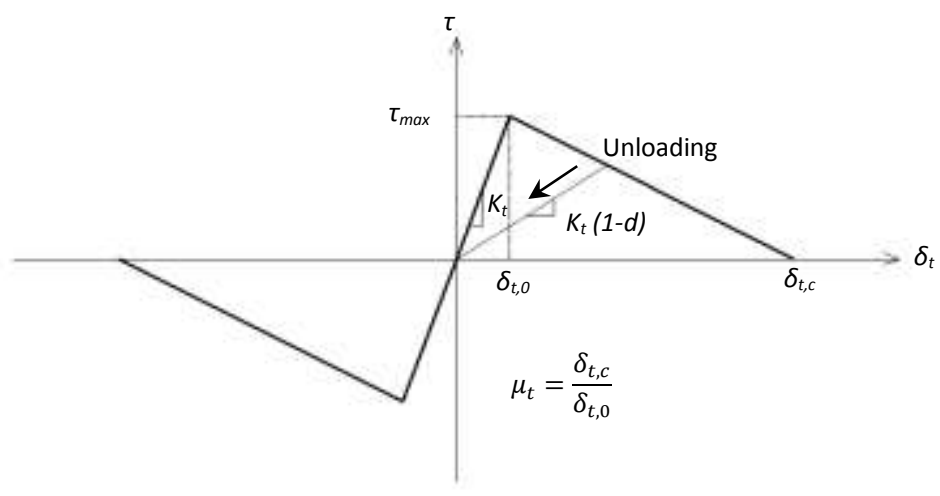

b) Mode-II fracture

Fig. 3 Cohesive zone constitutive model for SFRM 


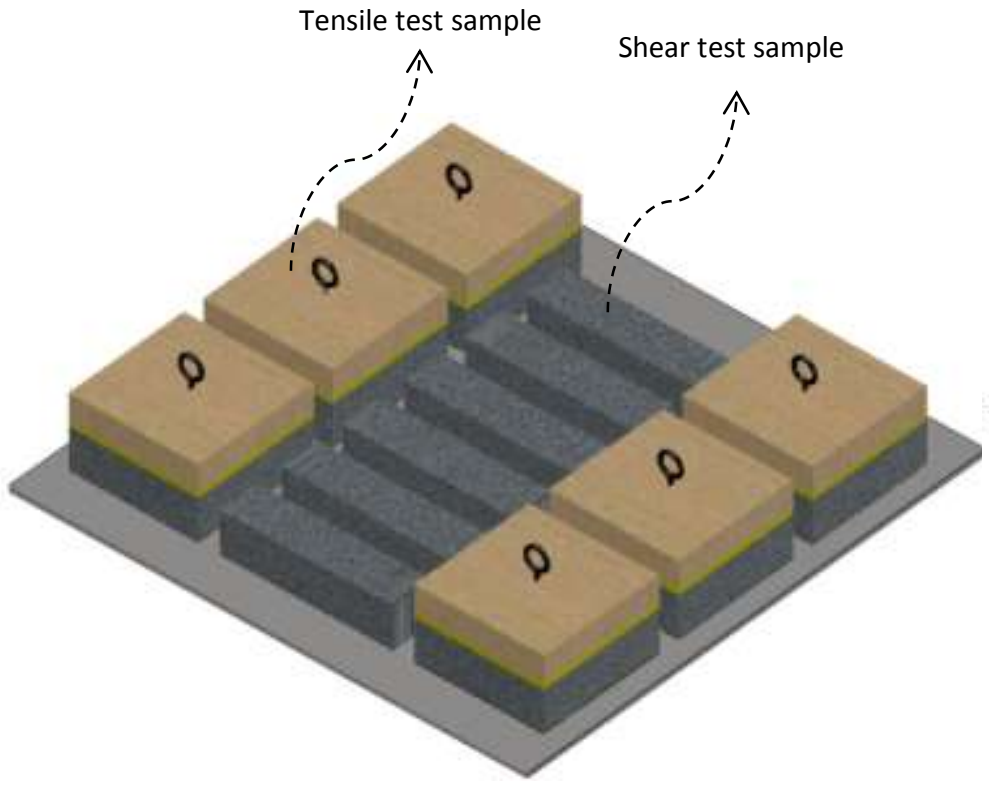

a) 3D view of SFRM samples

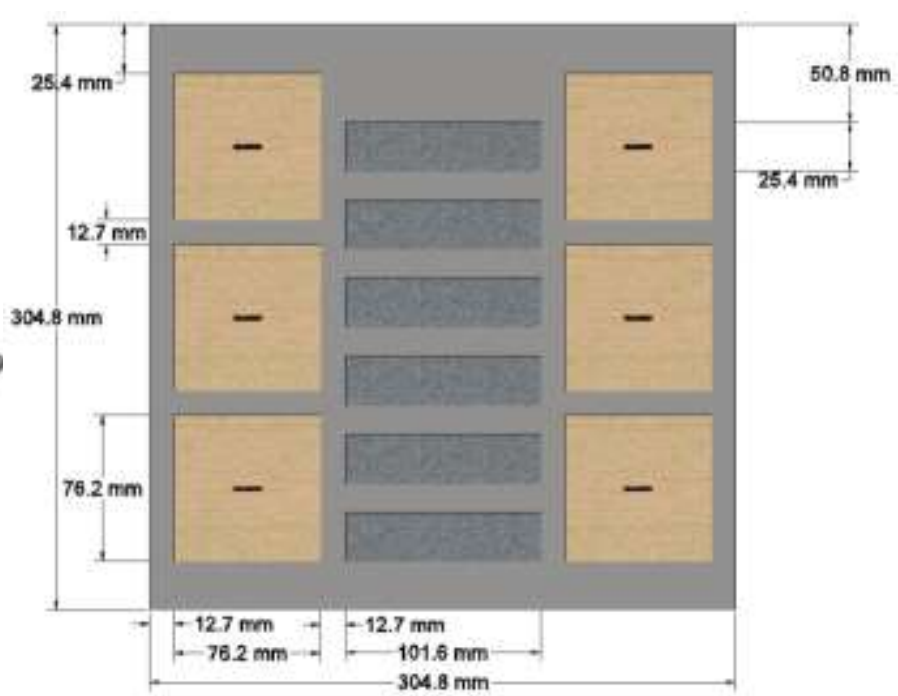

b) Test plate and SFRM sample dimensions

Fig. 4 Test plate geometry for measuring CZM parameters 


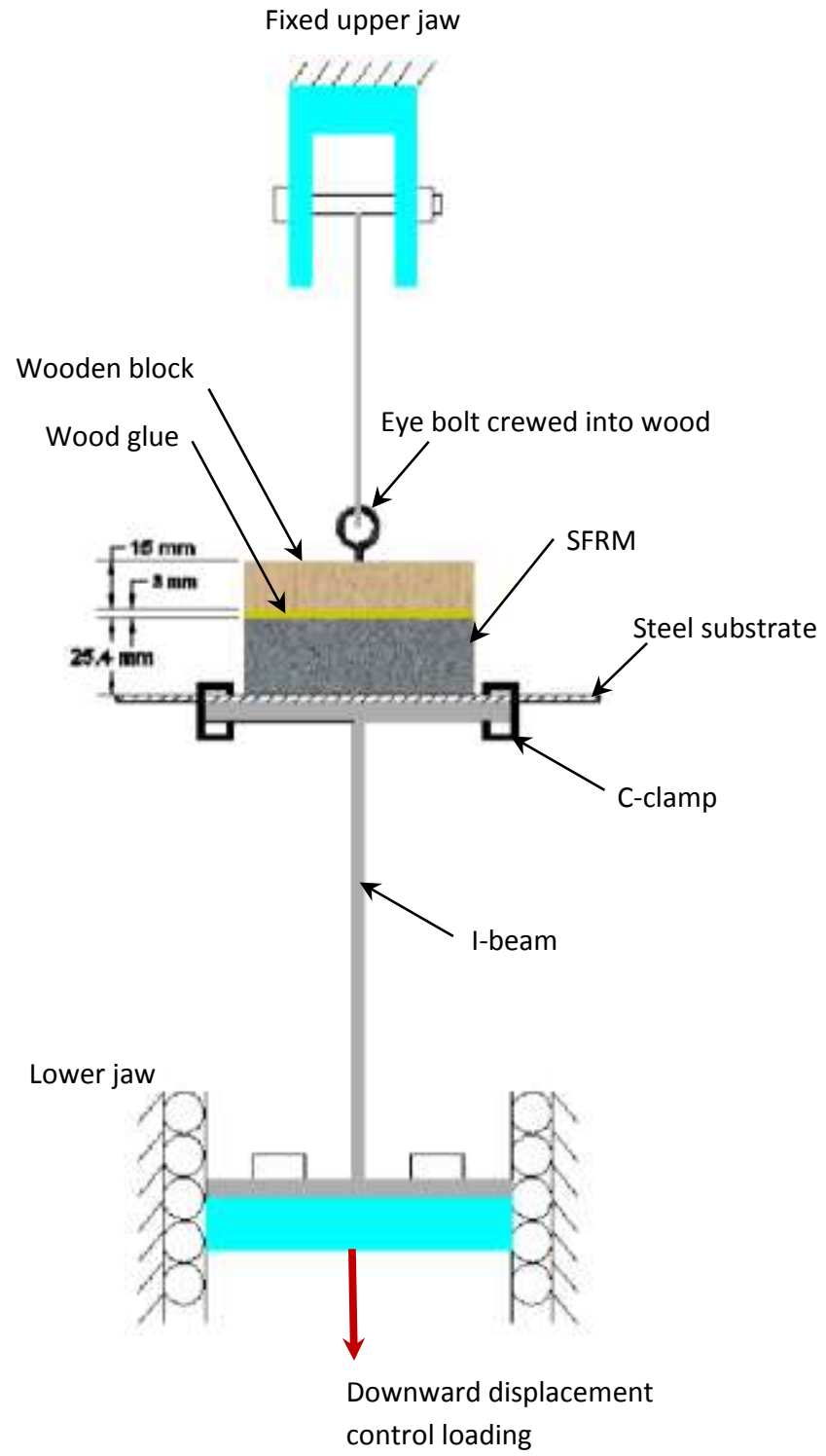

a) Test schematic for model-I delamination

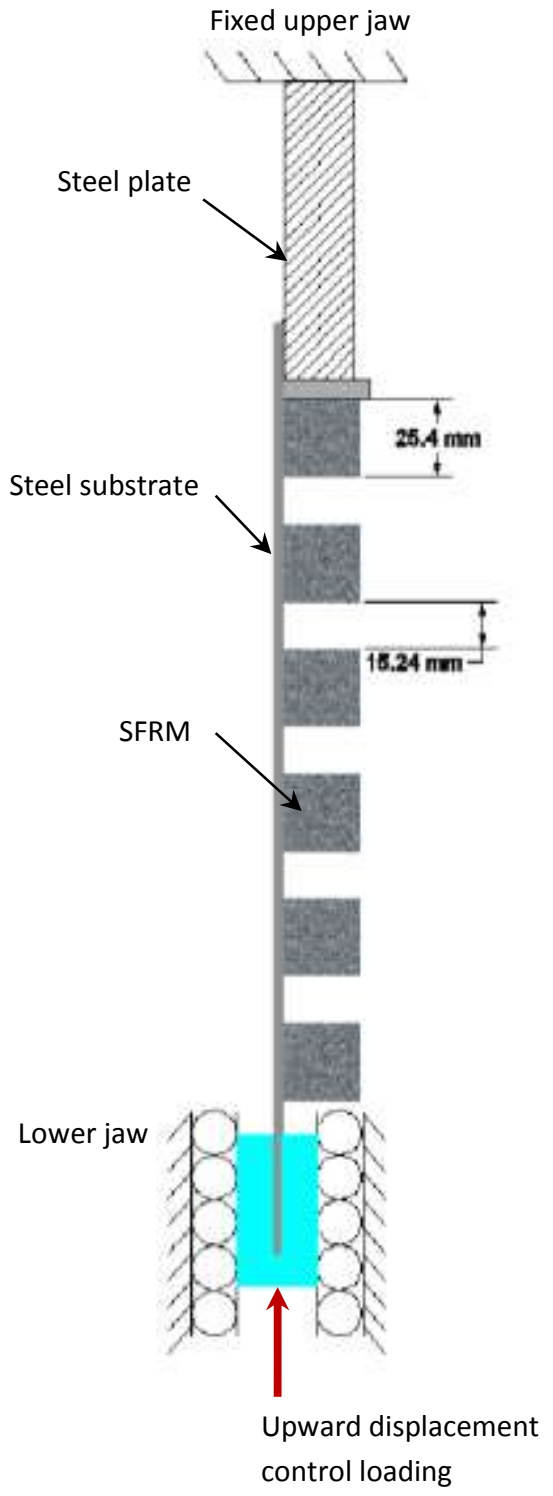

b) Test schematic for model-II delamination

Fig. 5 Schematic of test assembly for determination of CZM parameters 


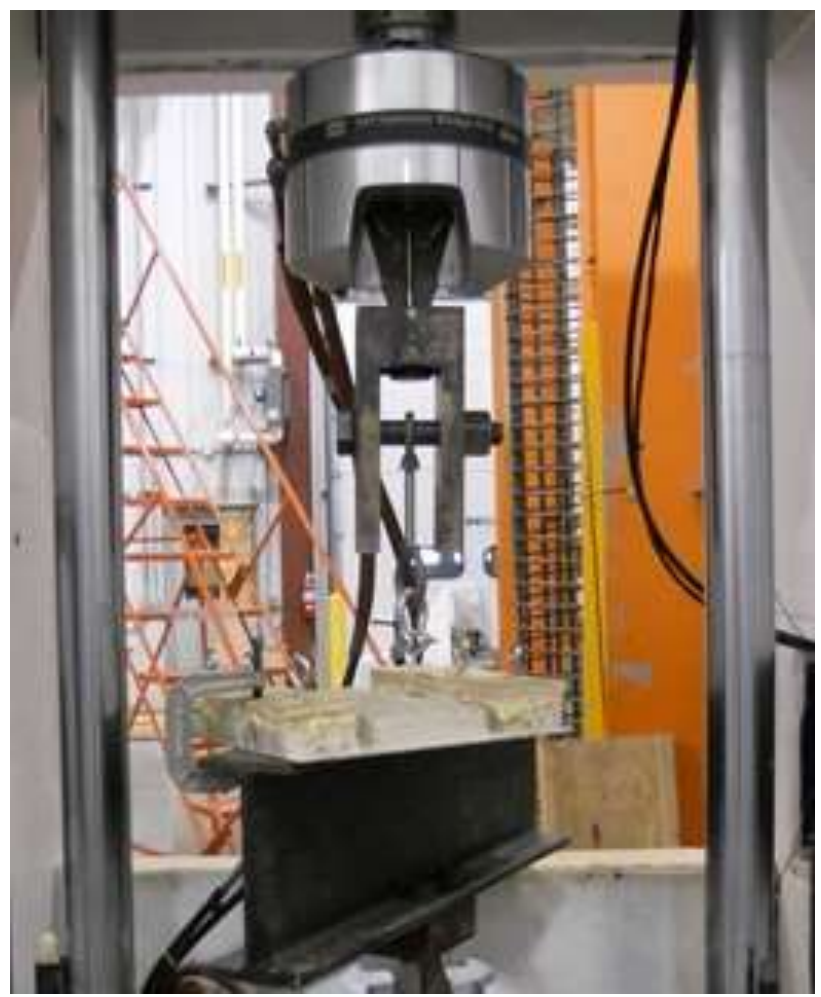

a) Test set up for model-I delamination

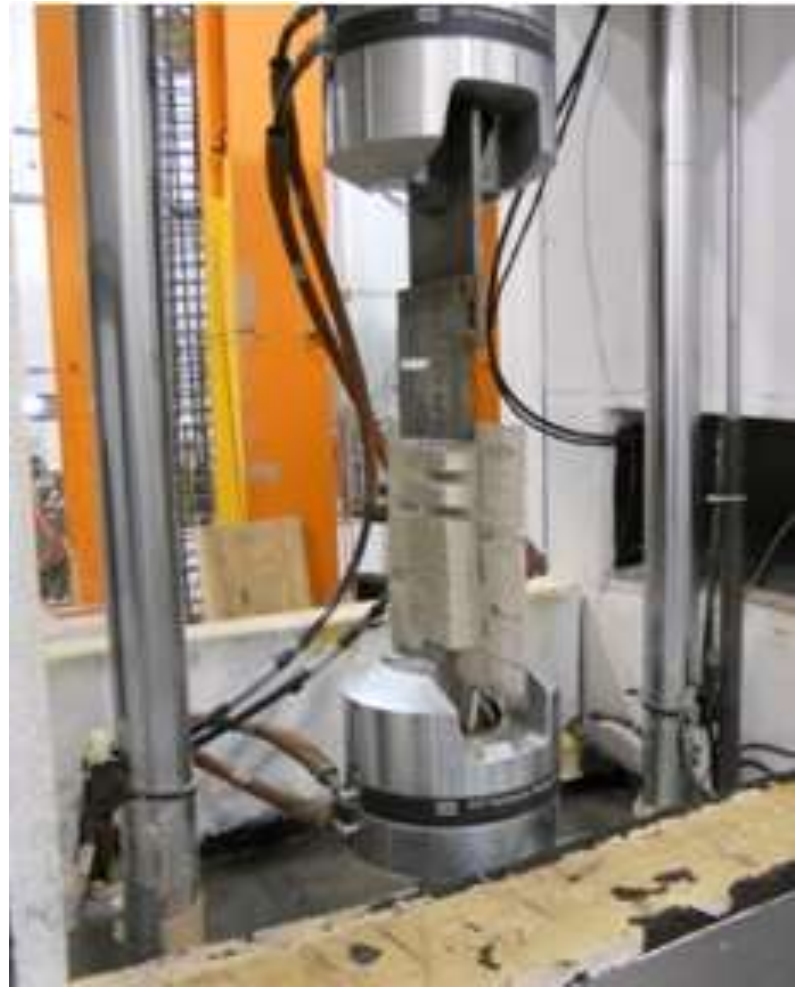

b) Test set up for model-II delamination

Fig. 6 Test set up designed for measuring CZM parameters at steel-SFRM interface 


\section{Figure 7}

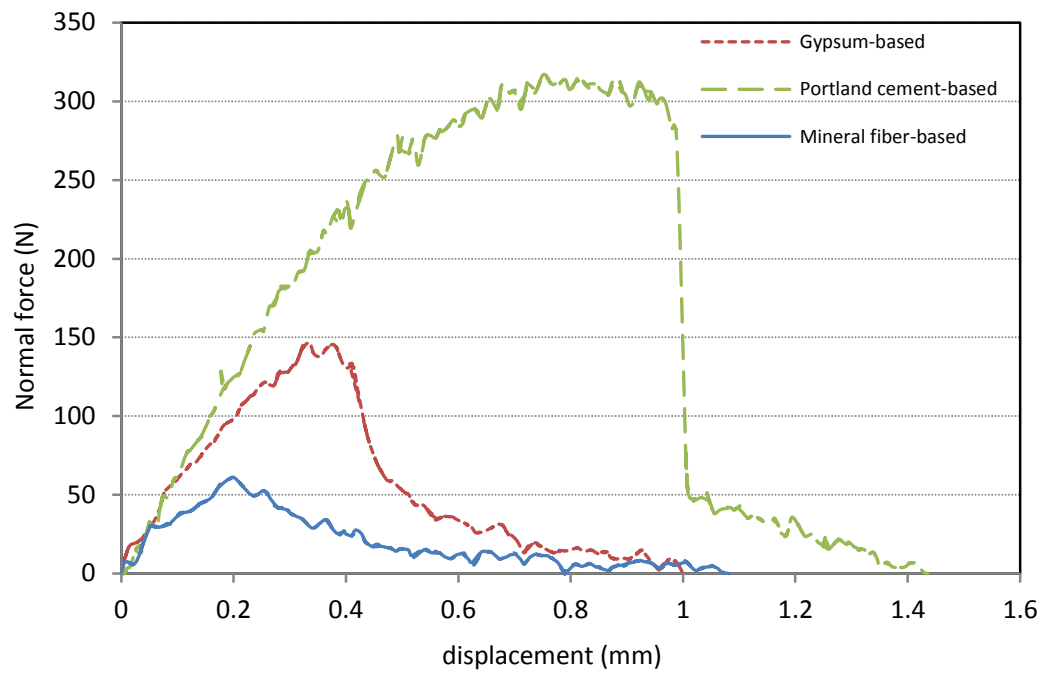

Fig. 7 Normal force-displacement relationship (Mode-I delamination) 
Figure 8

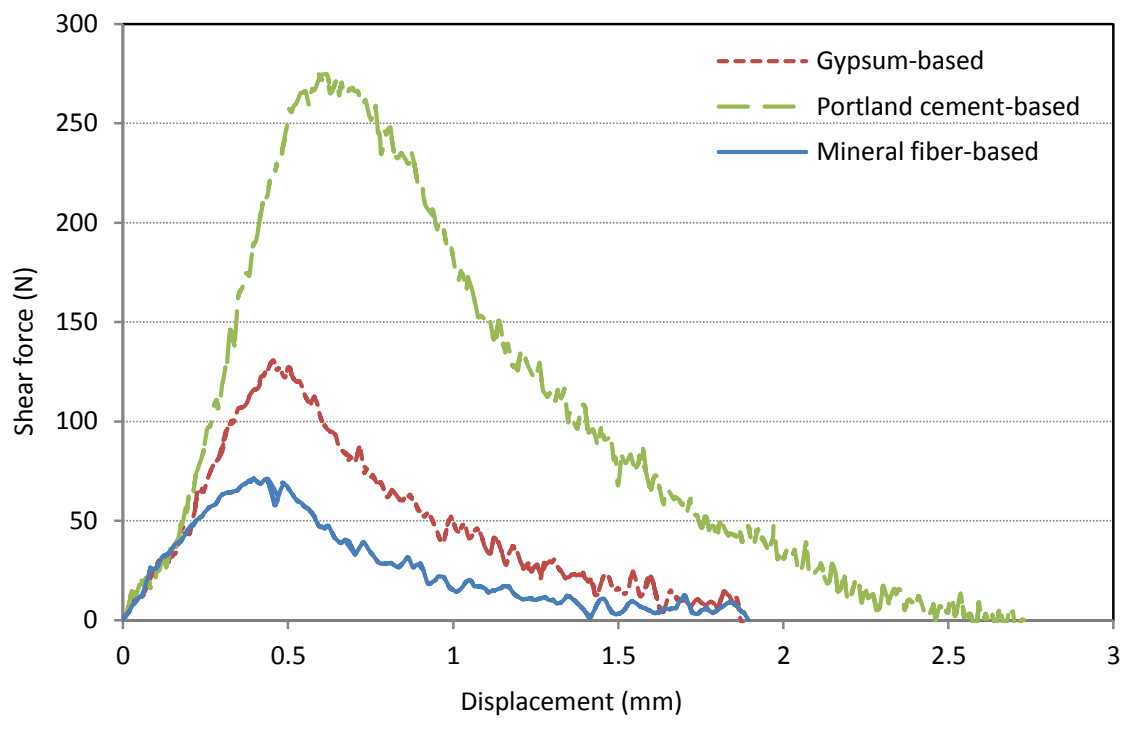

Fig. 8 Shear force-displacement relationship (Mode-II Delamination) 
Figure 9

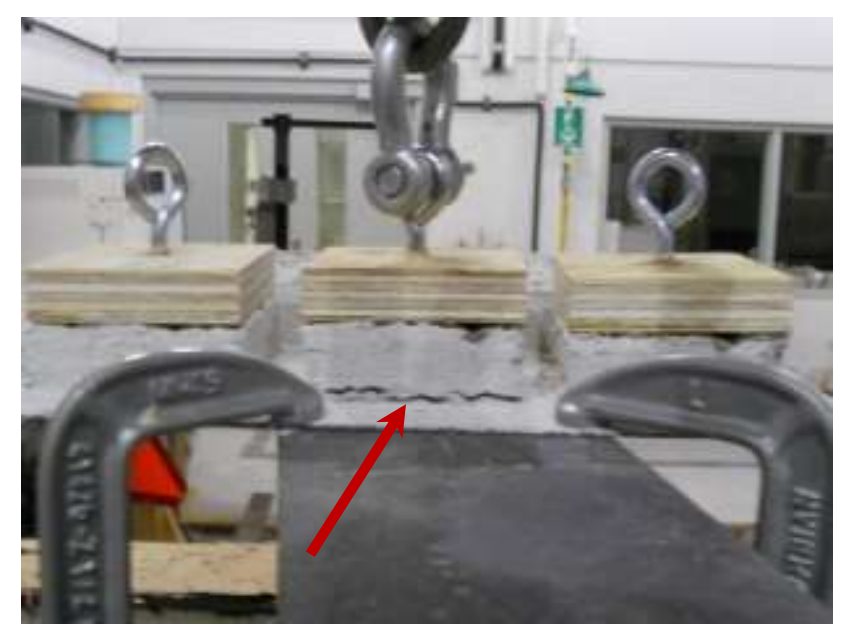

a) Fracture in typical tensile test specimen

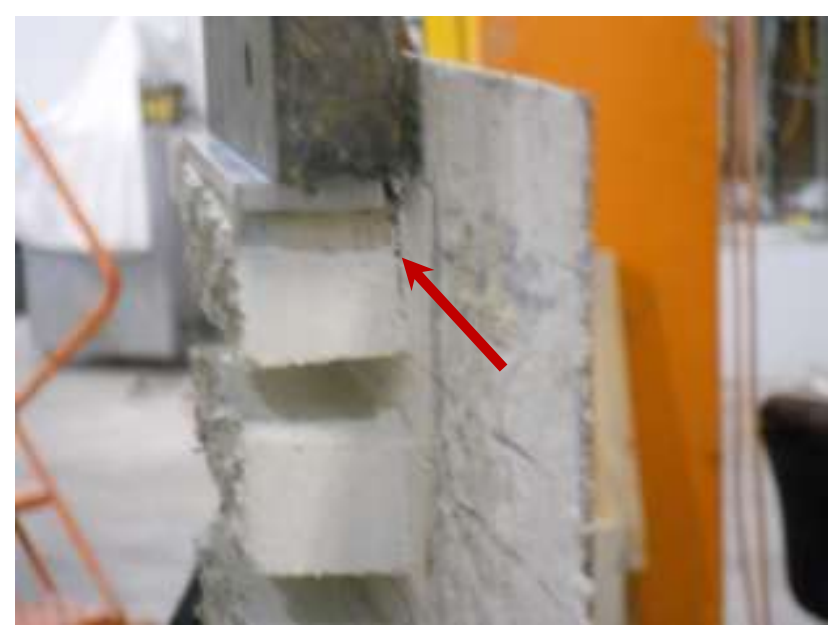

b) Fracture in typical shear test specimen

Fig. 9 Fracture at steel-SFRM interface observed in the experiments 


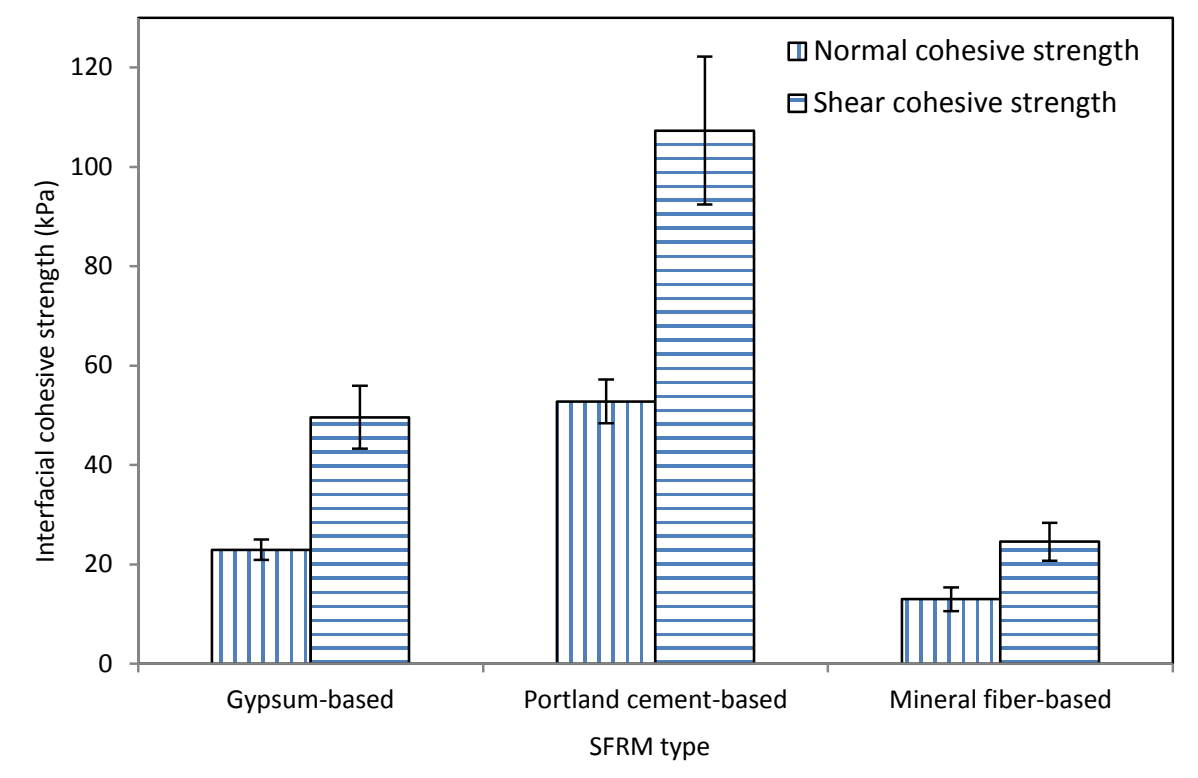

Fig. 10 Interfacial cohesive strength for three types of SFRM

Fig 10 Interfacial cohesive strength for three types of SFRM 
Figure 11

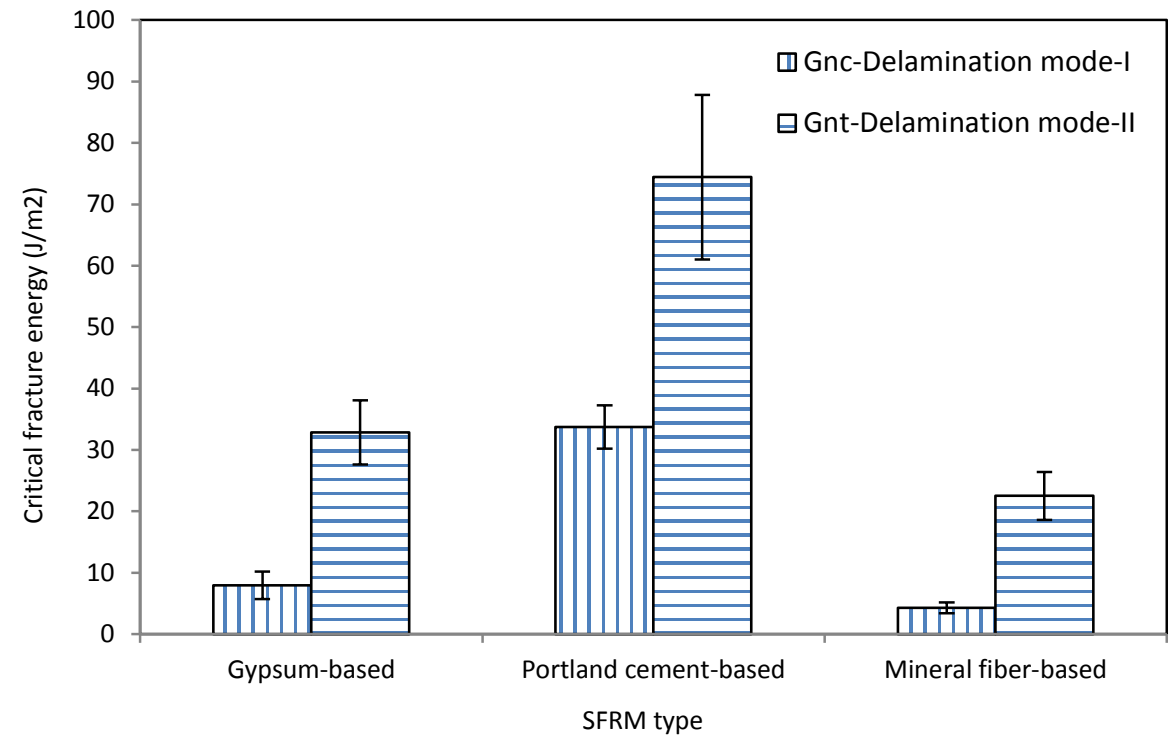

Fig. 11 Interfacial critical fracture energy for three types of SFRM 


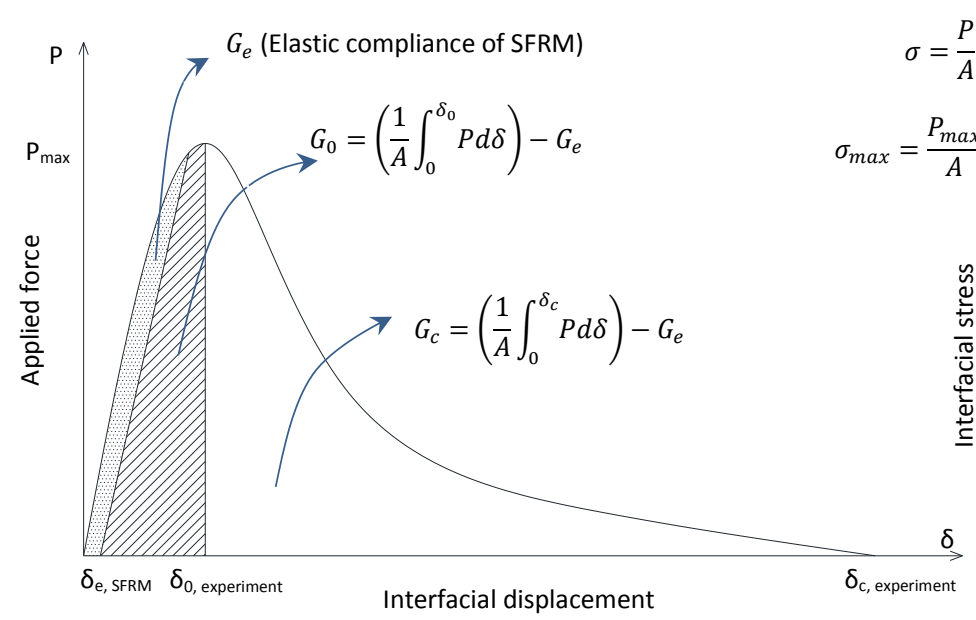

a) Experimental stress-displacement curve

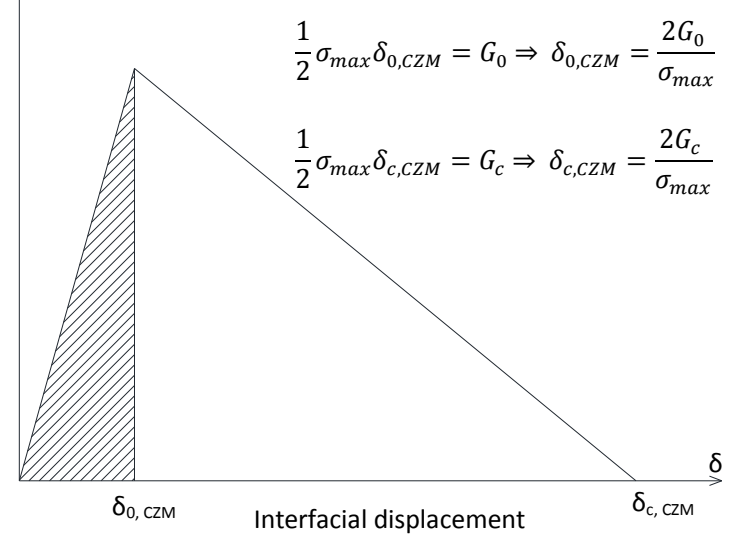

b) Cohesive zone model

Fig. 12 Determination of bilinear CZM parameters based on experimental results 


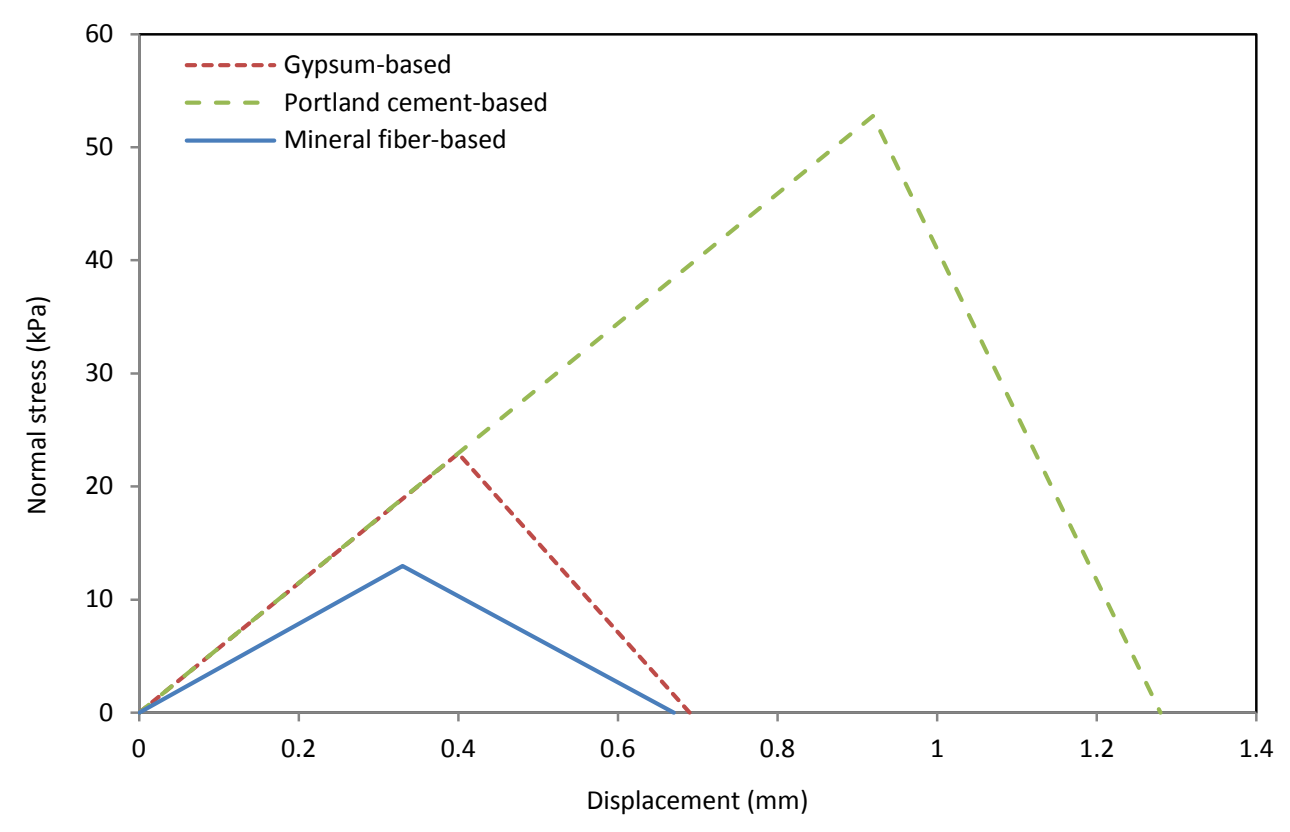

Fig. 13 Bilinear CZM for mode-I fracture determined from experiments 
Figure 14

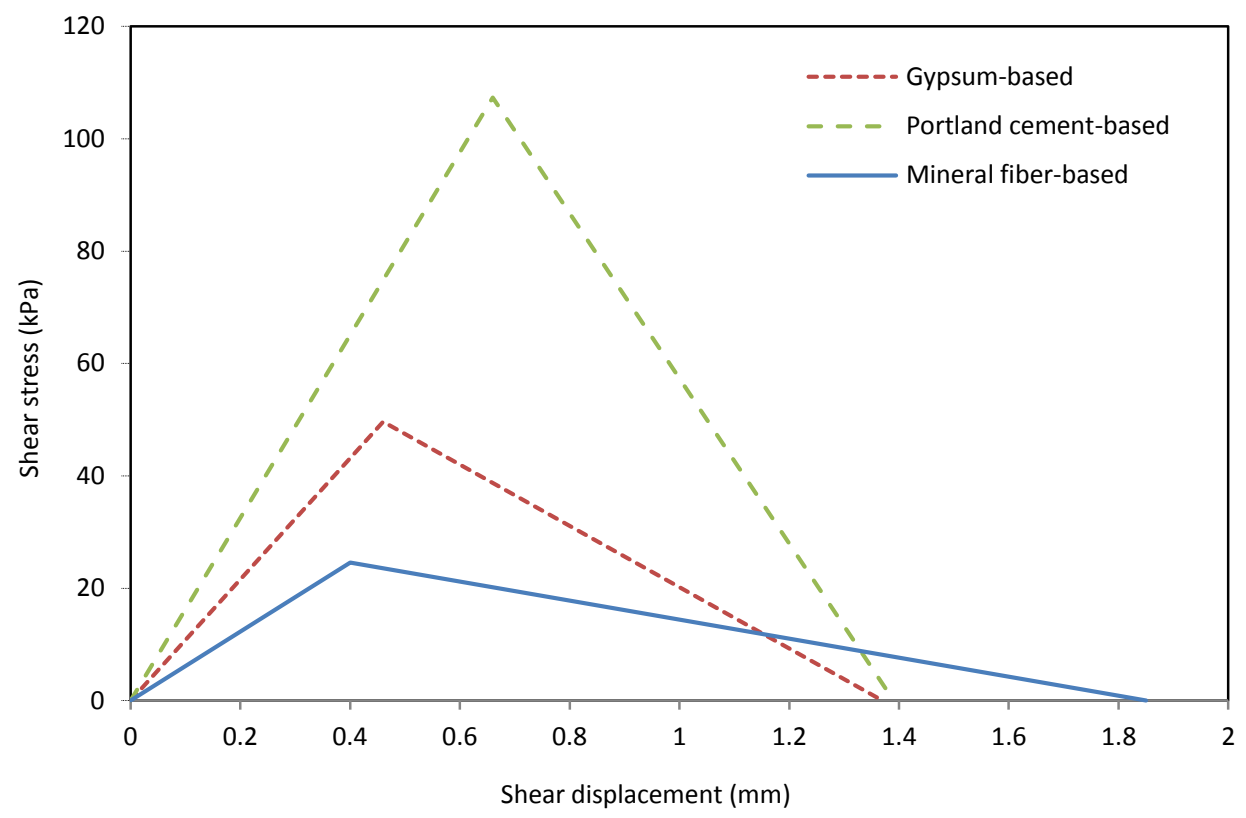

Fig. 14 Bilinear CZM for mode-II fracture determined from experiments

Fig. 14 Bilinear CZM for mode-II fracture determined from experiments

(1)

(1)



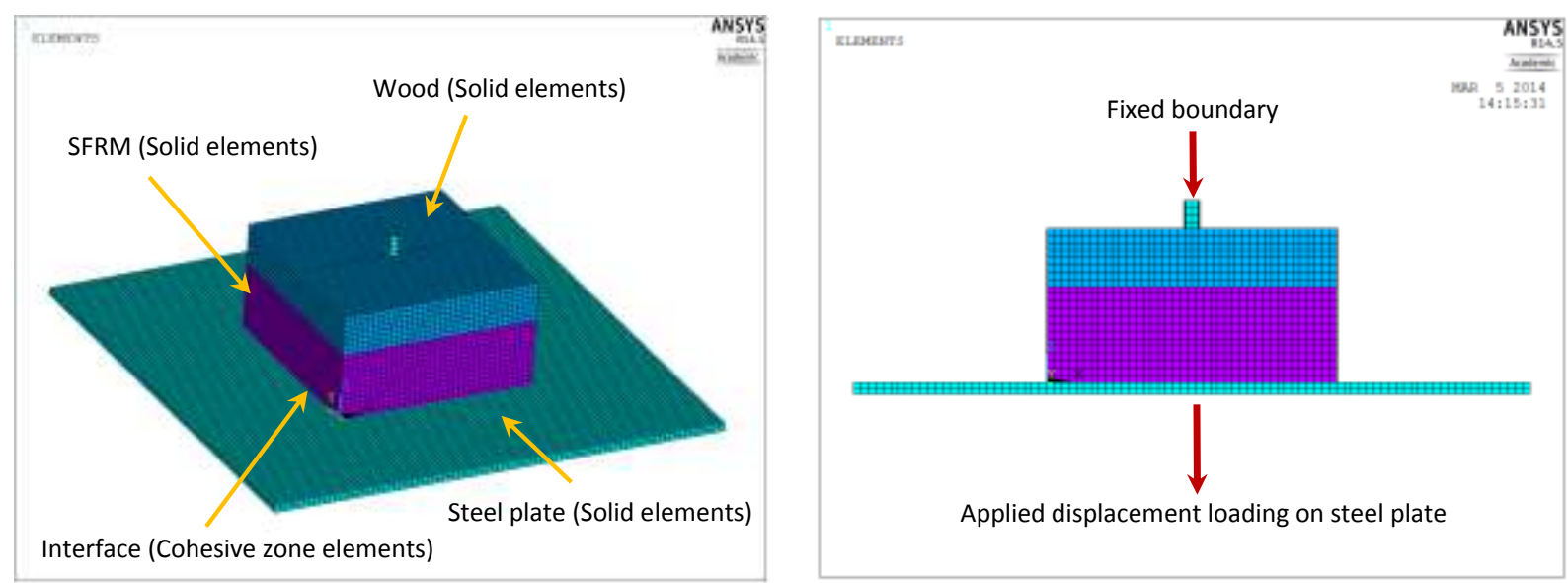

a) Finite element model of mode-I fracture specimen
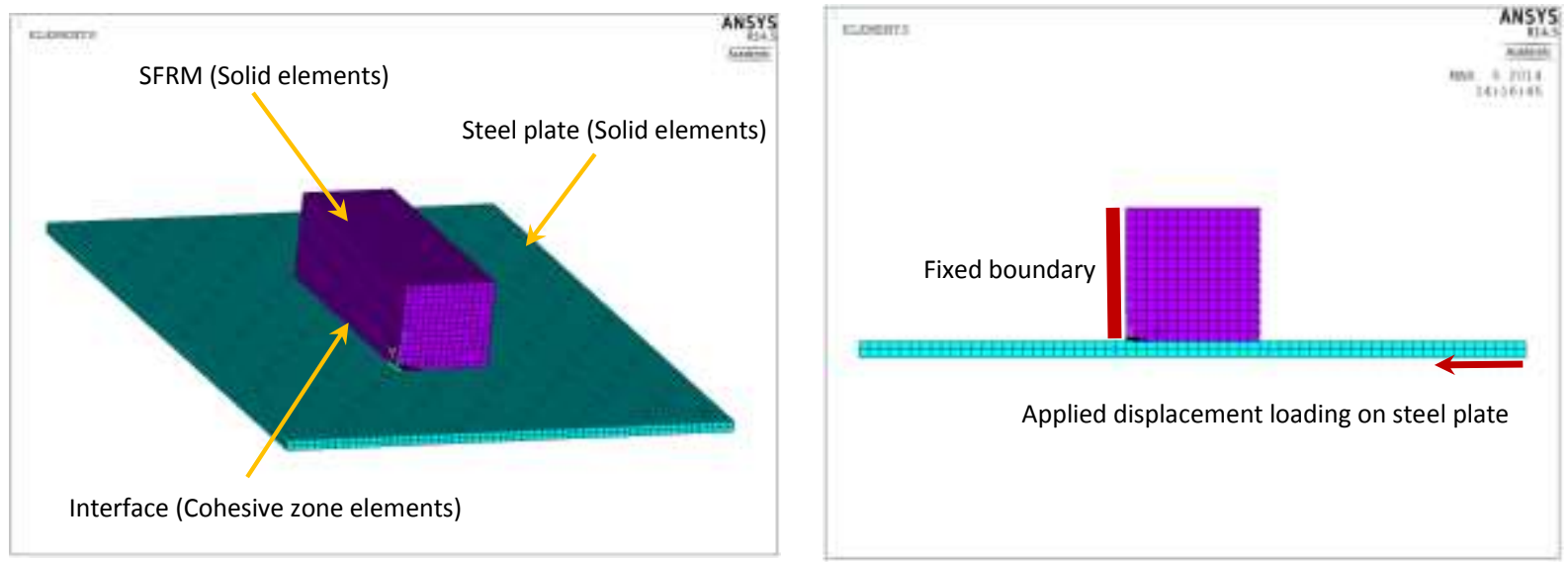

b) Finite element model of mode-II fracture specimen

Fig. 15 Finite element model of SFRM-steel assembly in mode-I and mode-II fracture experiments 


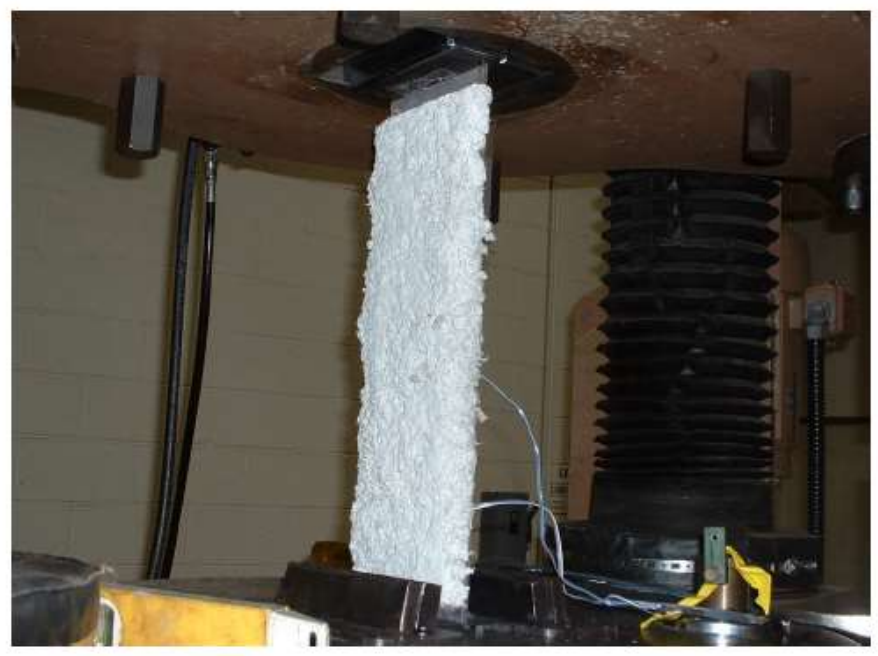

a) Plate test setup (Braxtan and Pessiki, 2011a)

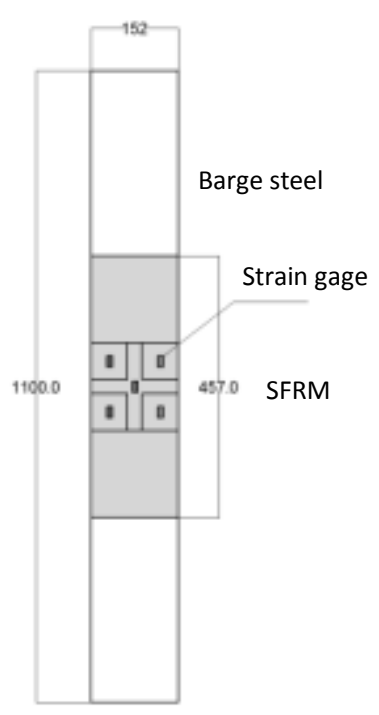

b) Plate geometry (dimensions are in $\mathrm{mm}$ )

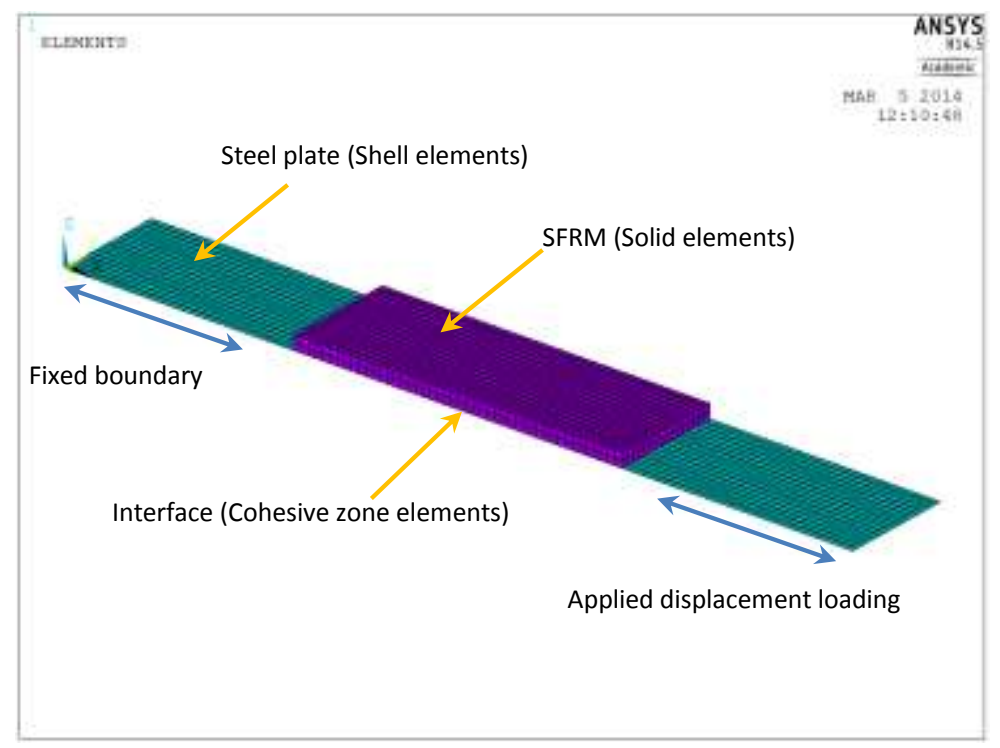

c) Finite element model of plate-SFRM

Fig. 16 Experimental setup and finite element model for plate covered with mineral fiber-based SFRM 


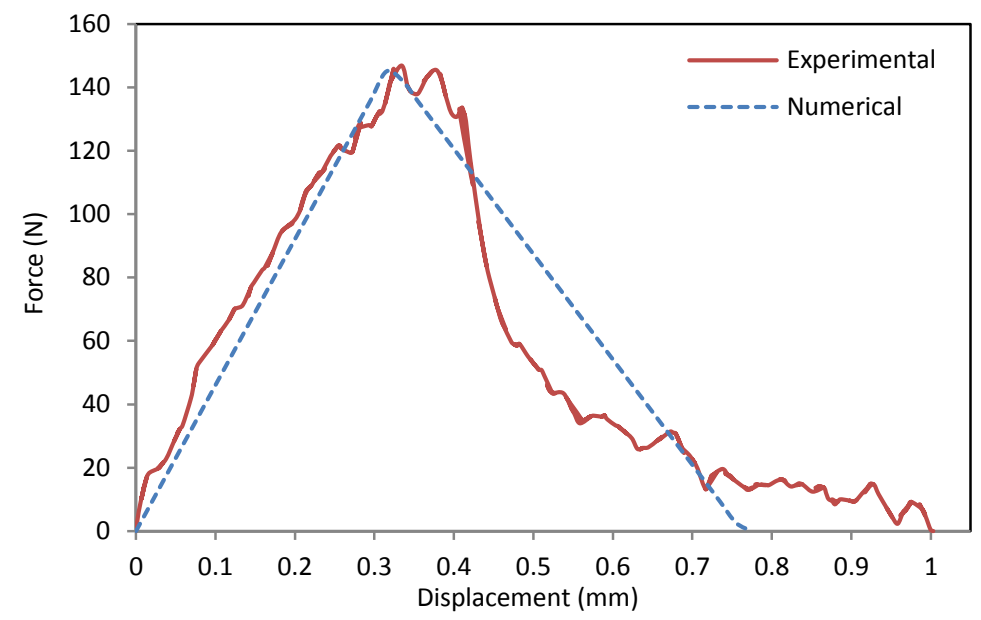

a) Gypsum-based SFRM

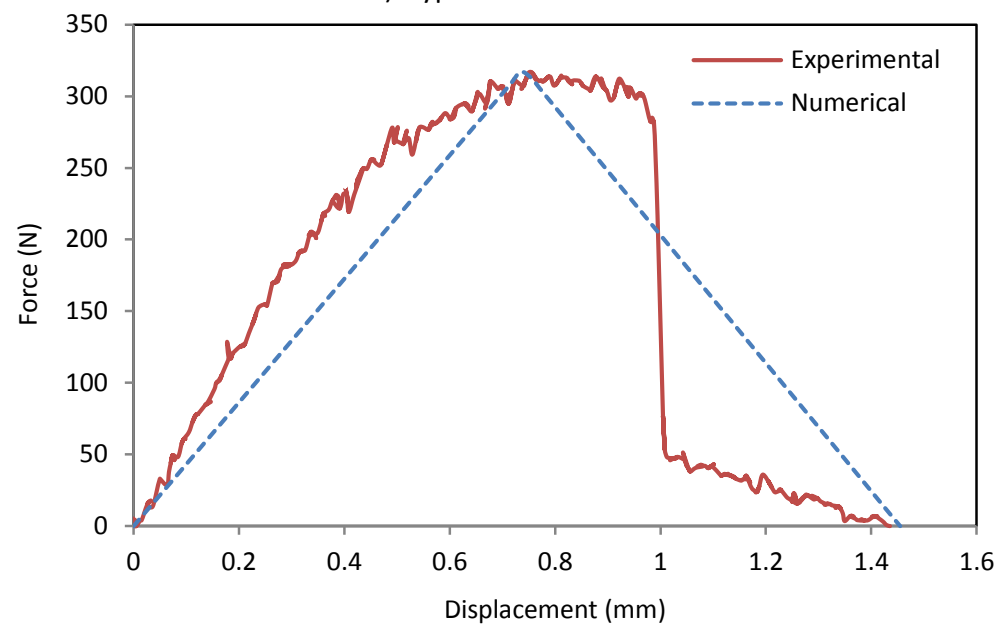

b) Portland cement-based SFRM

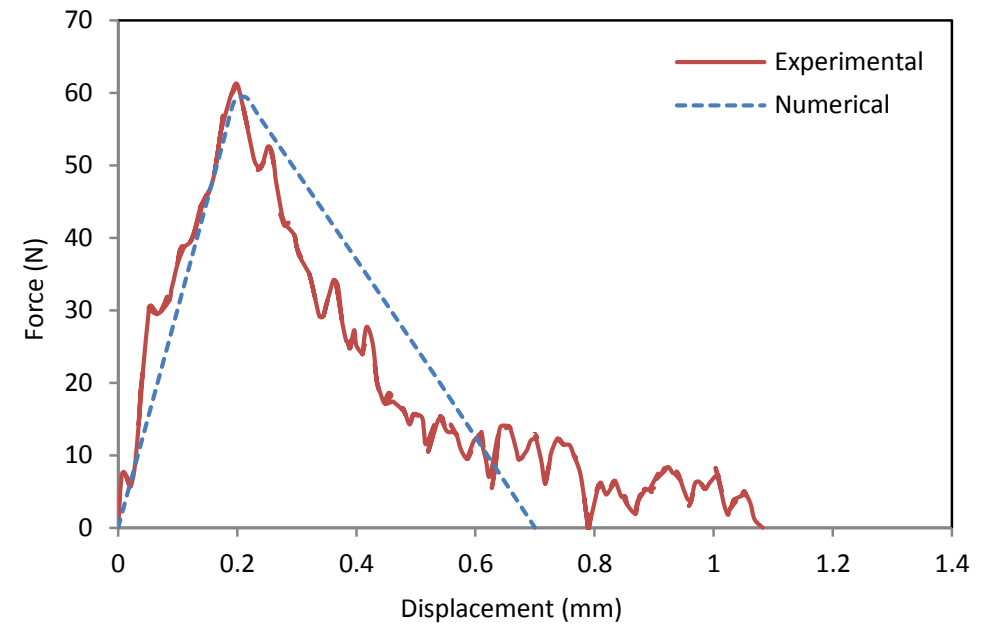

c) Mineral wool-based SFRM

Fig. 17 Comparison of force-displacement relationship predicted from numerical model with measured values from experiments for mode-I delamination 


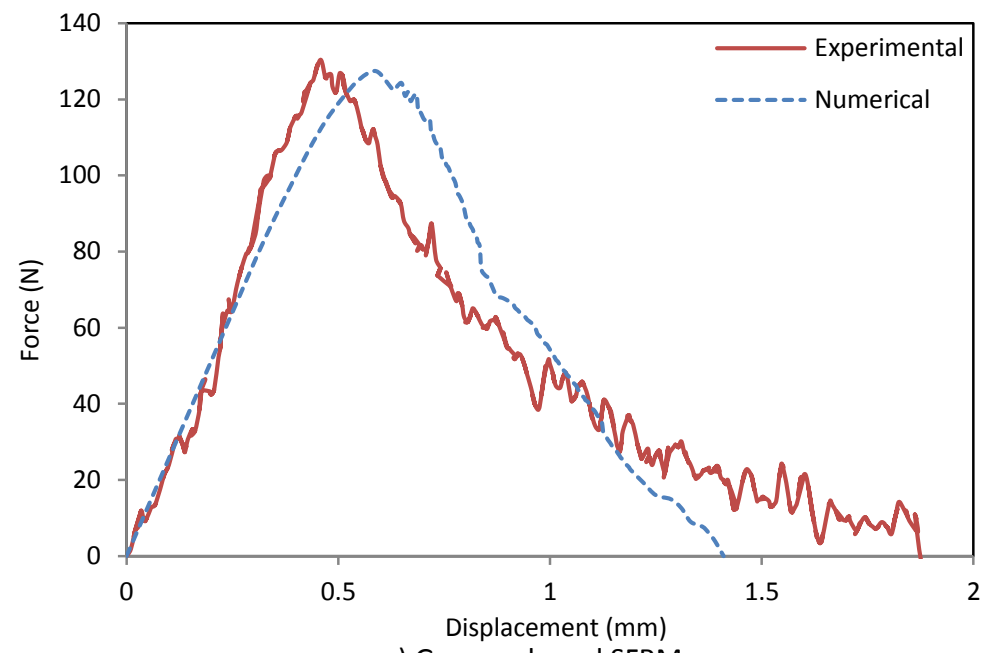

a) Gypsum-based SFRM

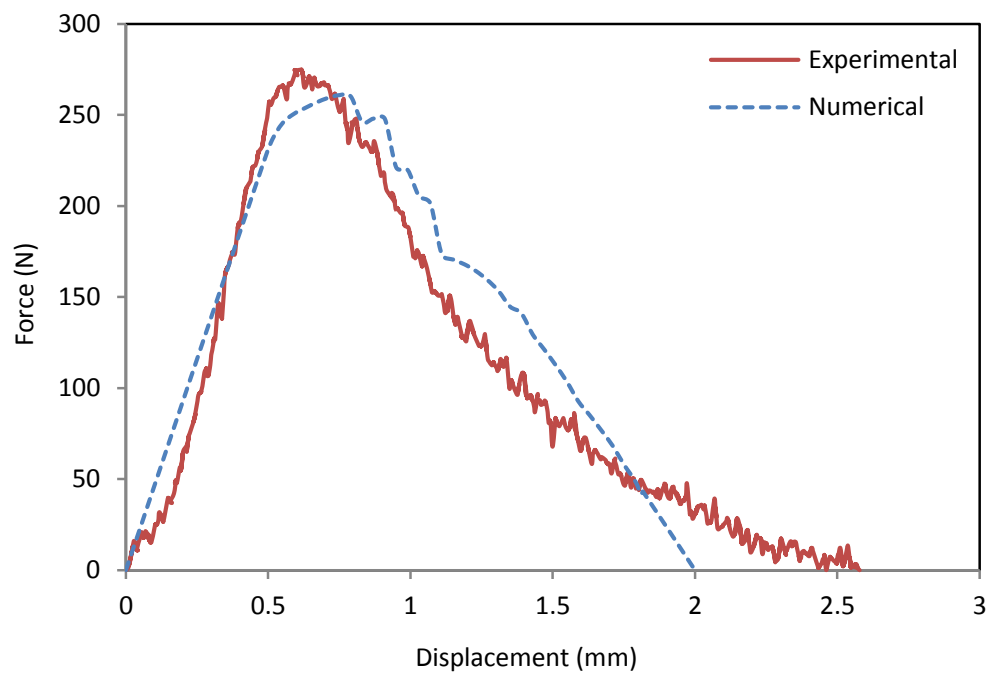

b) Portland cement-based SFRM

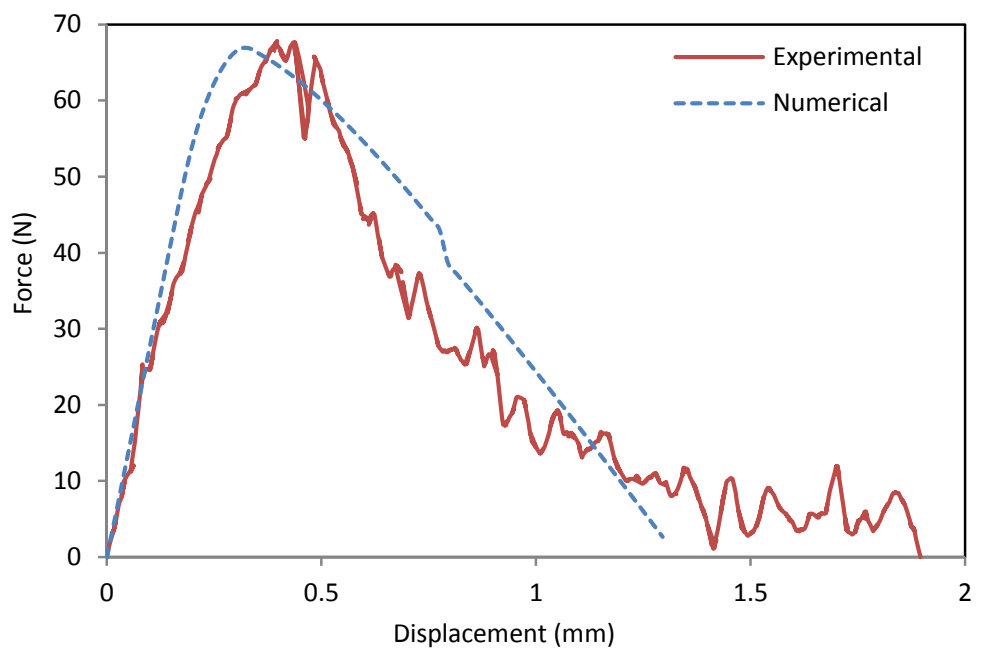

c) Mineral wool-based SFRM

Fig. 18 Comparison of force-displacement relationship predicted from numerical model with measured values from experiments for mode-II delamination 


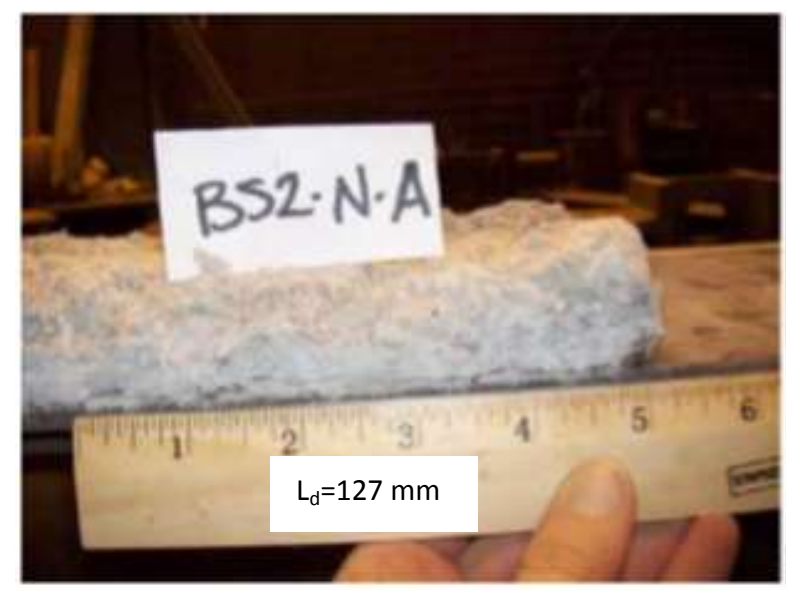

a) Test results (Braxtan and Pessiki, 2011a)

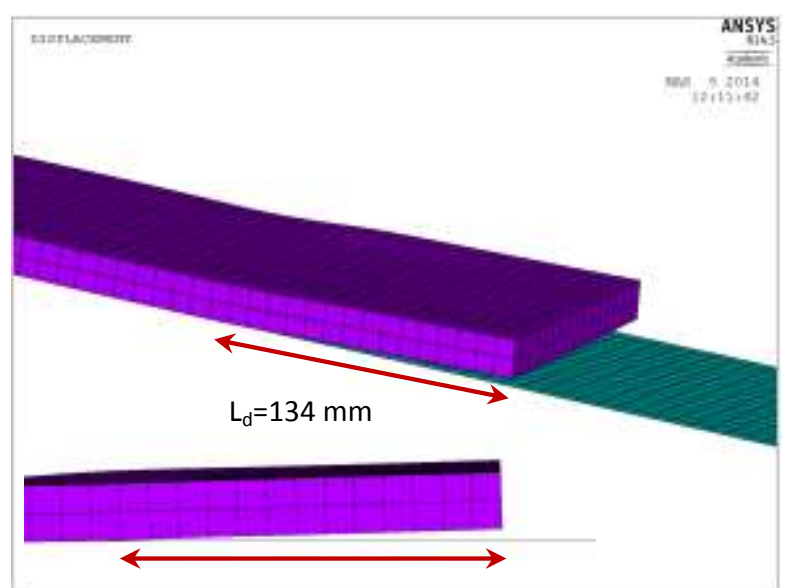

b) Simulation results

Fig. 19 Delamination length predicted and measured on a plate covered with mineral fiber-based SFRM 


\section{Nomenclature:}

SFRM: Spray applied fire resistive materials

CZM: Cohesive zone model

FPZ: Fracture process zone

LEFM: Linear elastic fracture mechanics

CTOD: Crack tip opening displacement

DCB: Double Cantilever Beam

ENF: End Notched Flexure

MTS: Material testing system

G: Fracture energy

$\sigma:$ Cohesive stress

$\delta$ : Interfacial opening displacment 